\title{
Assessment of CTF Needs for Modeling of Boiling Water Reactors
}

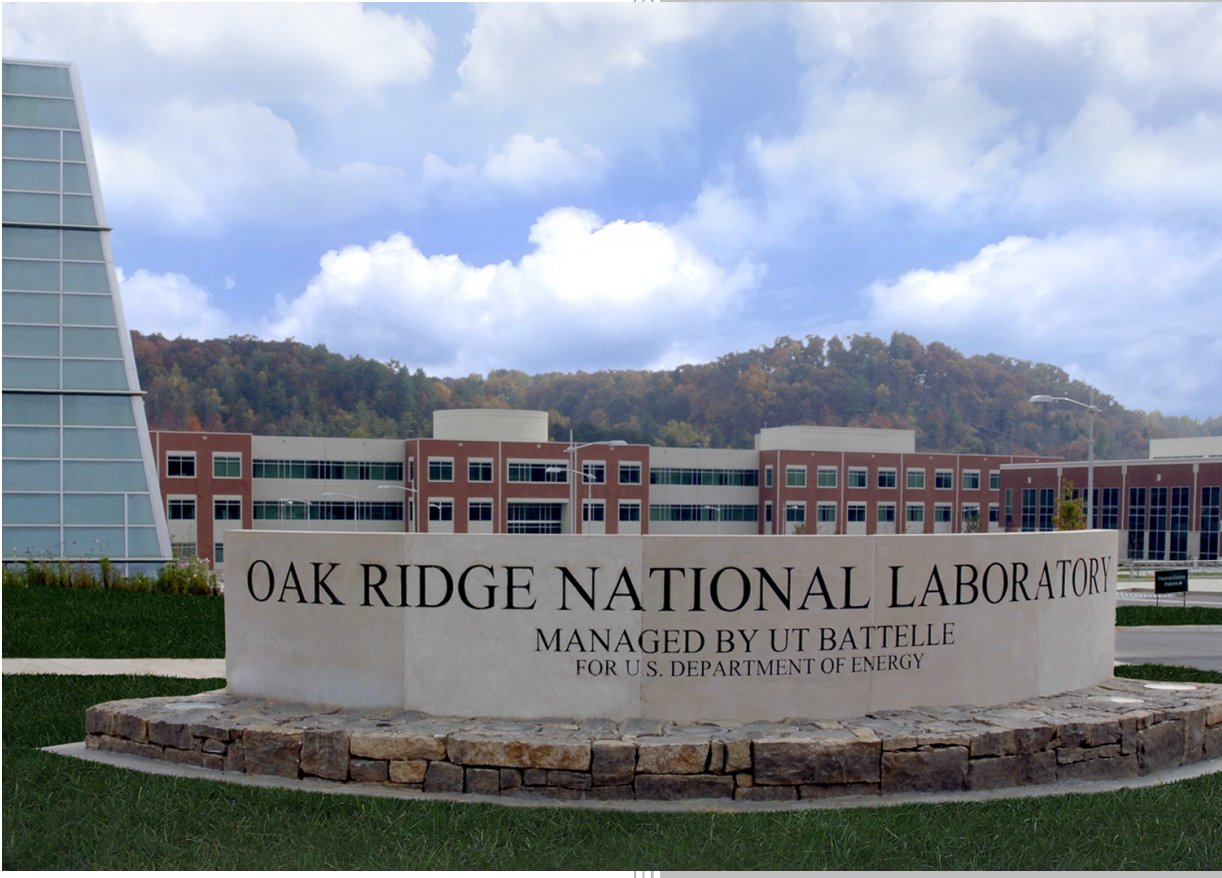

Approved for public release.

R. Salko

V. Kumar

Distribution is unlimited.

December 31, 2019 


\section{DOCUMENT AVAILABILITY}

Reports produced after January 1, 1996, are generally available free via US Department of Energy (DOE) SciTech Connect.

Website: www.osti.gov/

Reports produced before January 1, 1996, may be purchased by members of the public from the following source:

National Technical Information Service

5285 Port Royal Road

Springfield, VA 22161

Telephone: 703-605-6000 (1-800-553-6847)

TDD: $703-487-4639$

Fax: 703-605-6900

E-mail: info@ntis.gov

Website: http://classic.ntis.gov/

Reports are available to DOE employees, DOE contractors, Energy Technology Data Exchange representatives, and International Nuclear Information System representatives from the following source:

Office of Scientific and Technical Information

PO Box 62

Oak Ridge, TN 37831

Telephone: 865-576-8401

Fax: 865-576-5728

E-mail: report@osti.gov

Website: http://www.osti.gov/contact.html

This report was prepared as an account of work sponsored by an agency of the United States Government. Neither the United States Government nor any agency thereof, nor any of their employees, makes any warranty, express or implied, or assumes any legal liability or responsibility for the accuracy, completeness, or usefulness of any information, apparatus, product, or process disclosed, or represents that its use would not infringe privately owned rights. Reference herein to any specific commercial product, process, or service by trade name, trademark, manufacturer, or otherwise, does not necessarily constitute or imply its endorsement, recommendation, or favoring by the United States Government or any agency thereof. The views and opinions of authors expressed herein do not necessarily state or reflect those of the United States Government or any agency thereof. 
ORNL/TM-2020/3

Reactor Nuclear Systems Division

Assessment of CTF Needs for Modeling of Boiling Water Reactors
Authors
R. Salko
V. Kumar

Date Published: December 31, 2019

Prepared by

OAK RIDGE NATIONAL LABORATORY

Oak Ridge, TN 37831-6283

managed by

UT-Battelle, LLC

for the

US DEPARTMENT OF ENERGY

under contract DE-AC05-00OR22725 



\section{CONTENTS}

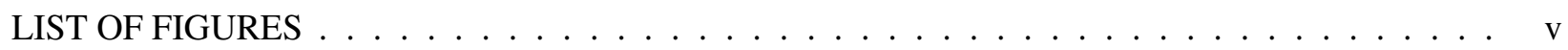

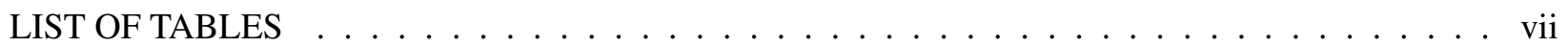

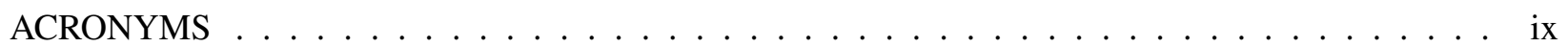

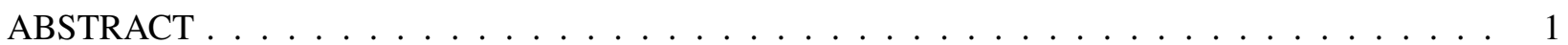

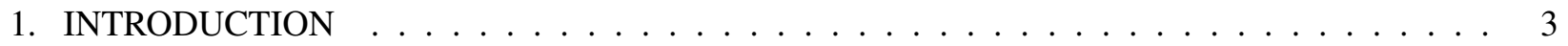

2. USER INTERFACE IMPROVEMENTS . . . . . . . . . . . . . . . . . . . . . 5

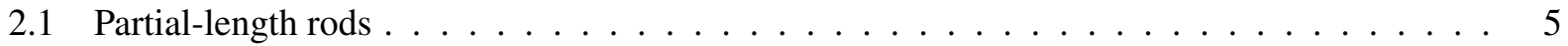

2.1.1 Testing options in CTF for modeling geometry . . . . . . . . . . . . . 5

2.1.2 Addition of a verification test to the geometry tables approach . . . . . . . . 6

2.1 .3 Future work . . . . . . . . . . . . . . . . . . . 10

2.2 VERA-CS HDF5 file support for BWR geometry . . . . . . . . . . . . . . 11

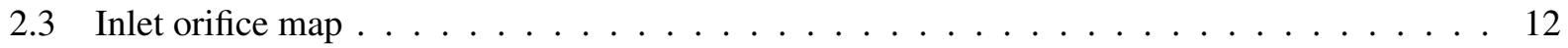

2.4 Expansion of $\mathrm{Xml} 2 \mathrm{ctf}$ regression testing $\ldots \ldots \ldots \ldots \ldots \ldots \ldots$

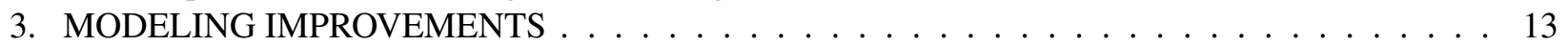

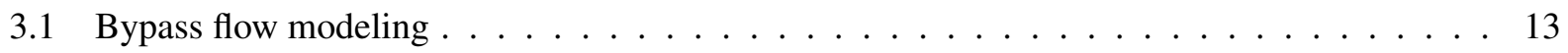

3.2 Two-phase closure model improvements . . . . . . . . . . . . . . . . . 14

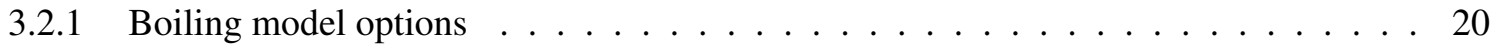

3.2 .2 Path Forward . . . . . . . . . . . . . . . . . . . . 24

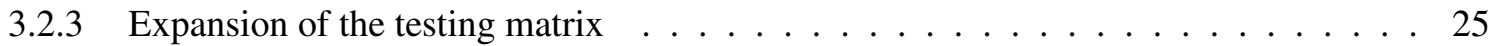

3.2 .4 Bartolomei tests . . . . . . . . . . . . . . . . . . 26

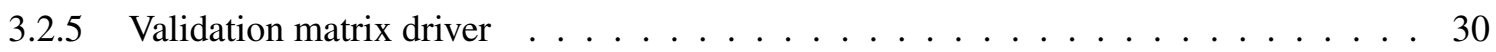

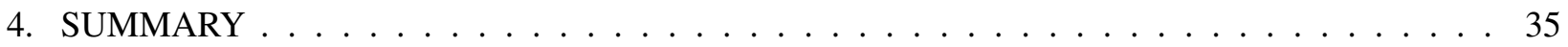

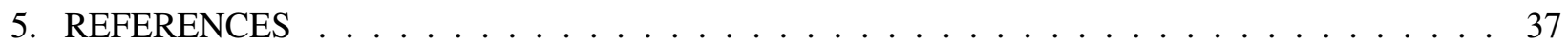





\section{LIST OF FIGURES}

1 Example of modeling a part-length rod using a multi-section model in CTF $\ldots \ldots$

2 Effect of modeling a part-length rod using a multisection model vs. a table-based approach. . 7

3 Example of flow expansion model geometry. . . . . . . . . . . . . . . 8

4 CTF staggered mesh for flow expansion test near point of expansion. . . . . . . . . . . . 9

5 Comparison of expected and calculated velocities in the expansion verification test. . . . . 10

6 Comparison of expected and calculated pressures in the expansion verification test. . . . . . 10

7 Comparison of CTF predicted average outlet void and measurements for BFBT void distribution cases. . . . . . . . . . . . . . . . . . . . . 16

8 Comparison of CTF predictions of void to measurements in the PSBT single-channel,

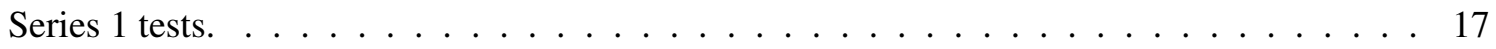

9 Two-phase pressure drop prediction of CTF for RISO tube tests compared to

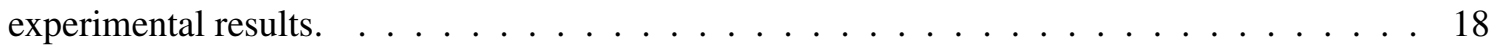

10 Two-phase pressure drop prediction of CTF for RISO tube tests compared to experimental results using the Lane closure models for annular-mist flow. . . . . . . . . . 19

11 CTF decision matrix for determining heat transfer regime (emphasis on selection of

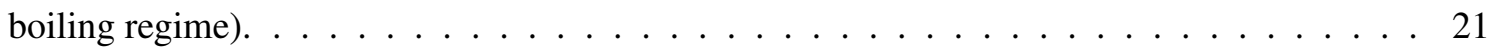

12 Comparison of CTF and experimental data of wall temperature, mean liquid temperature, and void fraction for Case $1 \ldots \ldots \ldots \ldots \ldots \ldots$

13 Comparison of CTF and experimental data for variation in mass flux at 70.0 bar and heat flux of $0.8 \mathrm{MW} / \mathrm{m}^{2} \ldots \ldots \ldots \ldots \ldots \ldots \ldots \ldots \ldots$

14 Comparison of CTF and experimental data for variation in mass flux at 70.0 bar and mass

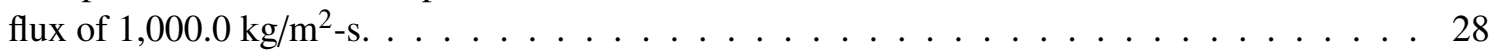

15 Comparison of CTF and experimental data for variation in mass flux at 150.0 bar and mass flux of $2000.0 \mathrm{~kg} / \mathrm{m}^{2}-\mathrm{s} . \ldots \ldots \ldots$. . . . . . . . . . . . . . . . 29

16 Comparison of CTF and experimental data for variation in system pressure at mass flux of $2000.0 \mathrm{~kg} / \mathrm{m}^{2}-\mathrm{s}$ and heat flux of $1.1 \mathrm{MW} / \mathrm{m}^{2} \ldots \ldots \ldots \ldots$. . . . . . . . . . . 29

17 Overall comparison of CTF vs. experimental void fractions using the subcooled boiling model of Thom. . . . . . . . . . . . . . . . . . . . . . . . 30

18 Overall comparison of CTF vs. experimental void fractions using the subcooled boiling model of Chen. . . . . . . . . . . . . . . . . . . . . . . . 



\section{LIST OF TABLES}

1 Summary of two-phase validation tests in CTF test matrix and requirements satisfied . . . 15

2 Ranges of operating conditions for the Bartolomei tests . . . . . . . . . . . . . . 26 



\section{ACRONYMS}

2D two-dimensional

BWR boiling water reactor

CASL Consortium for Advanced Simulation of Light Water Reactors

CFD computational fluid dynamics

CHF critical heat flux

CIPS crud-induced power shift

DNB departure from nucleate boiling

GE General Electric

HPC high-performance computing

HTC heat transfer coefficient

LWR light water reactor

NCSU North Carolina State University

ONB onset of nucleate boiling

OSV onset of significant void

PWR pressurized water reactor

RIA reactivity insertion accident

TKE turbulent kinetic energy

VERA Virtual Environment for Reactor Applications 



\begin{abstract}
The Consortium for Advanced Simulation of Light Water Reactors (CASL)-developed Virtual Environment for Reactor Applications (VERA) core simulator is undergoing further development to support development of boiling water reactor (BWR) models. CTF is the thermal-hydraulic component of VERA that is used for thermal feedback and prediction of thermal-hydraulic parameters of interest such as departure from nucleate boiling. CTF, being equipped with two-phase flow modeling capabilities, is applicable for BWR analysis; however, work is needed to improve usability of the code and bring its quality for these applications up to the standards required of VERA. While some work has been done in CASL for BWR applications by developing a BWR preprocessor, performing two-phase validation work, and implementing a modeling approach for the separated flow paths of BWR geometry, additional work is needed to make the capability more production level and to add critical required features. This report summarizes the current immediate needs in CTF that will improve its applicability to modeling of common BWR designs and nominal operating conditions. These improvements will focus on usability improvements (support of BWR geometric features in the CTF model) as well as modeling accuracy improvements for two-phase flow. A summary of current work done to prepare CTF for these changes is given. It is intended that these developments will be incrementally made over the coarse of the next two years of the project.
\end{abstract}





\section{INTRODUCTION}

CTF [14] is a thermal-hydraulic code originally developed for the analysis of light water reactor (LWR) geometry and operating conditions. CTF uses the subchannel approach for meshing the model and the two-fluid model for modeling two-phase flow. CTF includes a third field for modeling droplet motion independently of the liquid film. CTF has been extensively developed as part of the Consortium for Advanced Simulation of Light Water Reactors (CASL) program with the intention of supporting nominal pressurized water reactor (PWR) operating conditions (reactor depletion) and departure from nucleate boiling (DNB) conditions and for providing thermal-hydraulic boundary conditions in crud-induced power shift (CIPS) studies. While some work has been done to improve CTF for applications in modeling boiling water reactor (BWR) designs, further work is required. This report provides an overview of the immediate development needs required to adequately supporting modeling and simulation of BWRs using CTF.

CTF requirements can be divided into two main areas: (1) user interface improvements, which includes new input that CTF must consider for BWR geometry, and (2) code accuracy improvements. This report identifies the specific tasks to be accomplished in these two areas. To address user interface requirements, the CTF preprocessor Xml2ctf must be expanded to support part-length rods, and the CTF output writer must be expanded to support BWR geometry when writing results to the VERA HDF5 file. It will also be necessary to develop a suite of Xml2ctf regression tests that adequately cover the required BWR modeling requirements. These regression tests will be added to use in further development of Xml2ctf. To improve code accuracy, previous validation work has identified areas for improvement in CTF prediction of void content in small and large bubble flow regimes, as well as pressure drop in annular-mist flow. It is proposed that the validation matrix be expanded with additional tests to further investigate areas for improvement; these findings will be used to drive efforts to identify and implement new closure models and/or to recalibrate models to improve prediction accuracy. An additional task related to code accuracy is to model bypass flow using CTF. The initial approach will be to use lookup tables to determine bypass flow rates, and a parallel effort will be performed to investigate explicitly modeling the bypass flow. The following two sections cover these needs in more detail and present some preliminary development and analysis that has been conducted to facilitate future improvements. 



\section{USER INTERFACE IMPROVEMENTS}

\subsection{Partial-length rods}

Partial-length (part-length) fuel rods start at the bottom of the assembly and terminate part of the way up the assembly, resulting in empty spots in the rod lattice in the upper portion of the assembly. This causes a form loss to beg introduced, as well as a deceleration of the flow as the flow area opens up. If the flow regime is annular, then the film on the part-length rod will break off and will either merge into the films of other rods or will enter the droplet field.

\subsubsection{Testing options in CTF for modeling geometry}

This type of geometry can be modeled in CTF using one of two approaches. In the first approach, a multi-section model can be created in which the lower section contains normal rod-lattice geometry, and the upper section starts at the end of the part-length rod. An example using this approach is shown for a $3 \times 3$ geometry in Figure 1. The lower section is shown in 1a, and the upper section merges the four channels adjacent to the part-length rod into a channel where the rod ends (Figure 1b). The upper section simply sits on top of the lower section in the CTF model, and CTF handles distributing mass/momentum/energy from the channels in the lower section into the connected ones in the upper section. The part-length rod does not exist at all in the upper section of the model.

An alternative approach for modeling the part-length rod is to model a single section using the nominal rod-bundle geometry. In this approach, the part-length rod exists in the entire model, but the geometry modification tables are used to eliminate the effect of the rod's cross section area and the wetted perimeter on the four adjacent subchannels where the rod ends (Figure 1c). The part-length rod power generation is also eliminated at its point of disappearance. Therefore, the four adjacent channels are still modeled, but their area increases, while the wetted perimeter area decreases. By default, the gaps connecting the four central channels will still retain the geometry of the gaps with the rod present. It is also possible to apply a geometry modification to the width and length of these gaps to open them up. A lateral form loss coefficient is applied to the gaps to account for contraction and expansion of the flow moving through the gaps between the rods. Currently, it is not possible to remove this form loss as the rod disappears, but leaving the form loss in place it may not have a significant impact on the solution.

The first approach is likely more intuitive for modeling this geometry, but it presents challenges in terms of model setup. The first challenge is that the $\mathrm{Xml2ctf}$ preprocessor was developed with the assumption that the model is single section. Changing this assumption would complicate code structure and would require substantial modifications. The second challenge is that BWR geometry can contain several groups of part-length rods of differing lengths. In this case, a different section would be needed for the termination of each group, which may be challenging when creating a model.

The second approach will be easier to implement because once a part-length pin is identified, a table eliminating the rod effects can be created and linked to that rod in the CTF model.

To compare the effects of the modeling approaches, a simple $3 \times 3$ model was created, which is a subregion of a General Electric (GE) $10 \times 10$ assembly model. The model has uniform radial and axial power, is single phase, and has a part-length rod in the center location which ends at $1 \mathrm{~m}$. The model was generated using a 


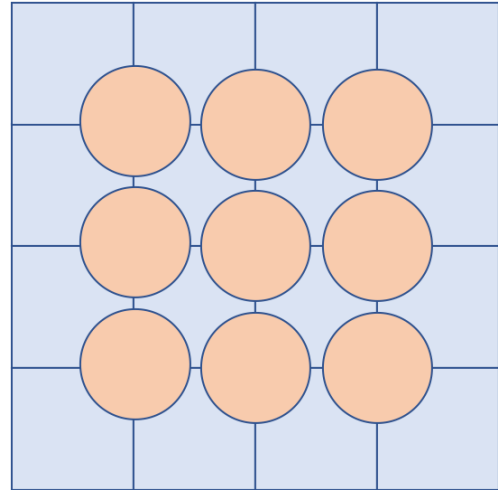

(a) Lower section has normal rod-bundle subchannel geometry.

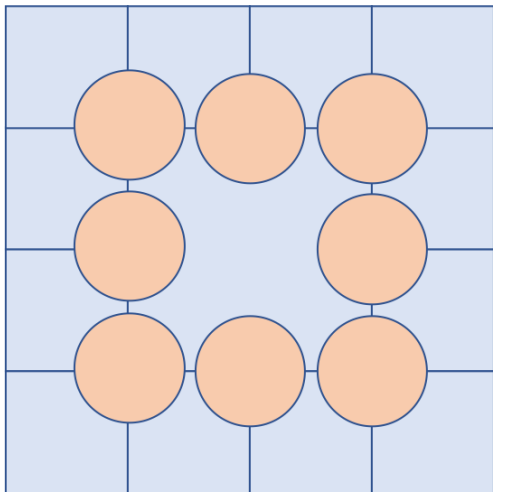

(b) In the upper section, the part-length rod is missing from the geometry, and the four subchannels that were surrounding the rod are now merged into a single subchannel.

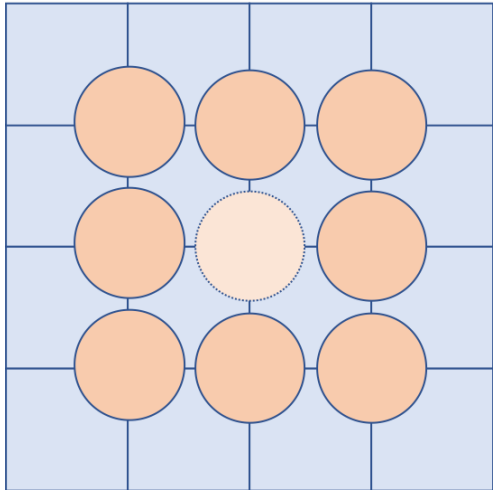

(c) The part length rod can be modeled using one section. A geometry-forcing function is specified on the rod so that its effect on the adjacent channel cross sectional area and wetted perimeter is eliminated when the rod disappears.

Figure 1. Example of modeling a part-length rod using a multi-section model in CTF

multi-section model and a table-based approach. The predicted velocity profile for both model types is shown in Figure 2 for a normal channel that is not affected by a part-length rod and an affected channel. As shown, there is a less than $1 \%$ difference in velocity profile prediction when comparing the results from the two approaches.

In the table-based model, no treatment is applied to the gaps, so they retain their original width, length, and loss coefficient. This model must be expanded to two-phase flow conditions to ensure that the behavior will still be similar under realistic conditions. Furthermore, a nonuniform power distribution should be applied to drive more cross flow and to further examine the effect of gap treatment.

\subsubsection{Addition of a verification test to the geometry tables approach}

A code verification test was added to ensure that the pressure drop effects (form loss due to rod disappearance, reduction in friction, and deceleration pressure gain) and velocity changes match the analytical expectations when modeling the rod disappearance using the table-based approach. This simple geometry was modeled in CTF and was compared to a hand-calculated solution. The hand-calculated solution, as well as the process of comparing it to CTF, was scripted in Python and added as a unit test in the CTF testing framework. This test is documented in the CTF V\&V manual [14].

The flow expansion problem involves axial flow expanding into a more open cross sectional area. To capture this effect, the model is set up in CTF using a flow area and a wetted perimeter axial modification table. This test ensures that CTF correctly predicts the deceleration of the fluid, the frictional pressure drop in lower and upper sections of the model, the form loss pressure drop, and the deceleration pressure rise. The model is set up for single-phase flow to ensure that an analytical solution can easily be calculated. 


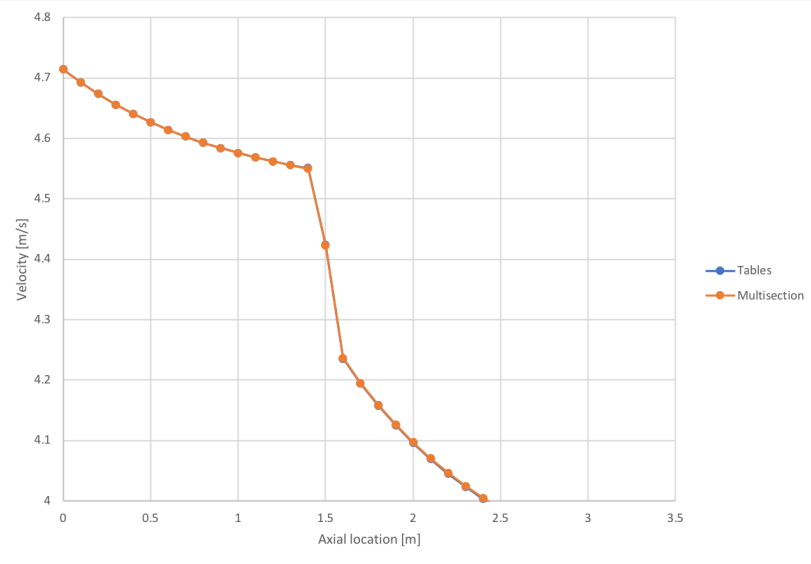

(a) Predicted velocity distribution in channel not affected by part-length rod in simple subregion part-length model.

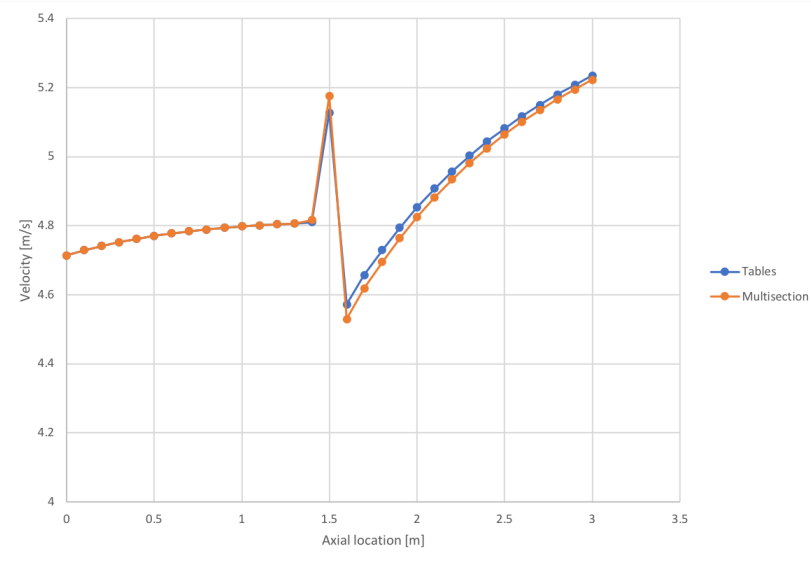

(b) Predicted velocity distribution in channel affected by part-length rod disappearance in simple subregion part-length model.

Figure 2. Effect of modeling a part-length rod using a multisection model vs. a table-based approach.

The model includes two channels connected to one rod, and the rod disappears half way up the model. A schematic of the model is shown in Figure 3. The model length is $2.0 \mathrm{~m}$, with the part-length rod disappearing at $1.0 \mathrm{~m}$ from the inlet. The inlet boundary conditions have a total mass flow rate of $0.9227 \mathrm{~kg} \mathrm{~s}^{-1}$, the inlet temperature is $200^{\circ} \mathrm{C}$, and the outlet pressure is $150 \mathrm{bar}$. The model is unheated. The nominal flow area is $1.2332 \times 10^{-4} \mathrm{~m}^{2}$, the wetted perimeter of each channel is $5.2723 \times 10^{-2} \mathrm{~m}$, and the diameter of the rod is $9.5 \times 10^{-3} \mathrm{~m}$. The width of the gap between the two channels is $3.1 \times 10^{-3} \mathrm{~m}$, and its length from channel to channel is $0.0126 \mathrm{~m}$. A lateral form loss coefficient of 0.5 is applied in the gap, and a form loss coefficient is also applied at the location of the expansion.

To make an analytical solution possible, the liquid density is set to a constant value of $900 \mathrm{~kg} \mathrm{~m}^{-3}$, and the friction factor is set to a constant of 0.1 . Since mass flow rate will be conserved over the geometric expansion, the velocity in the expanded region can be related to the inlet velocity as follows:

$$
\begin{aligned}
\dot{m}_{\text {in }} & =\dot{m}_{\text {out }} \\
\rho v_{\text {in }} A_{\text {in }} & =\rho v_{\text {out }} A_{\text {out }} \\
v_{\text {out }} & =\frac{A_{\text {in }}}{A_{\text {out }}} v_{\text {in }},
\end{aligned}
$$

where "in" and "out" refer to the inlet and outlet of the model, $\rho$ is the liquid density, $A$ is the cross sectional flow area, and $v$ is the liquid velocity. The frictional form loss is calculated as follows:

$$
\frac{d P}{d z}_{f}=\frac{1}{2 D_{h}} f \rho v^{2}
$$

where $f$ is the Darcy friction factor, $D_{h}$ is the hydraulic diameter, and $\frac{d P}{d z}$ is the pressure drop per unit length. Since velocity will be one of two values, there will be different frictional pressure drops in the 


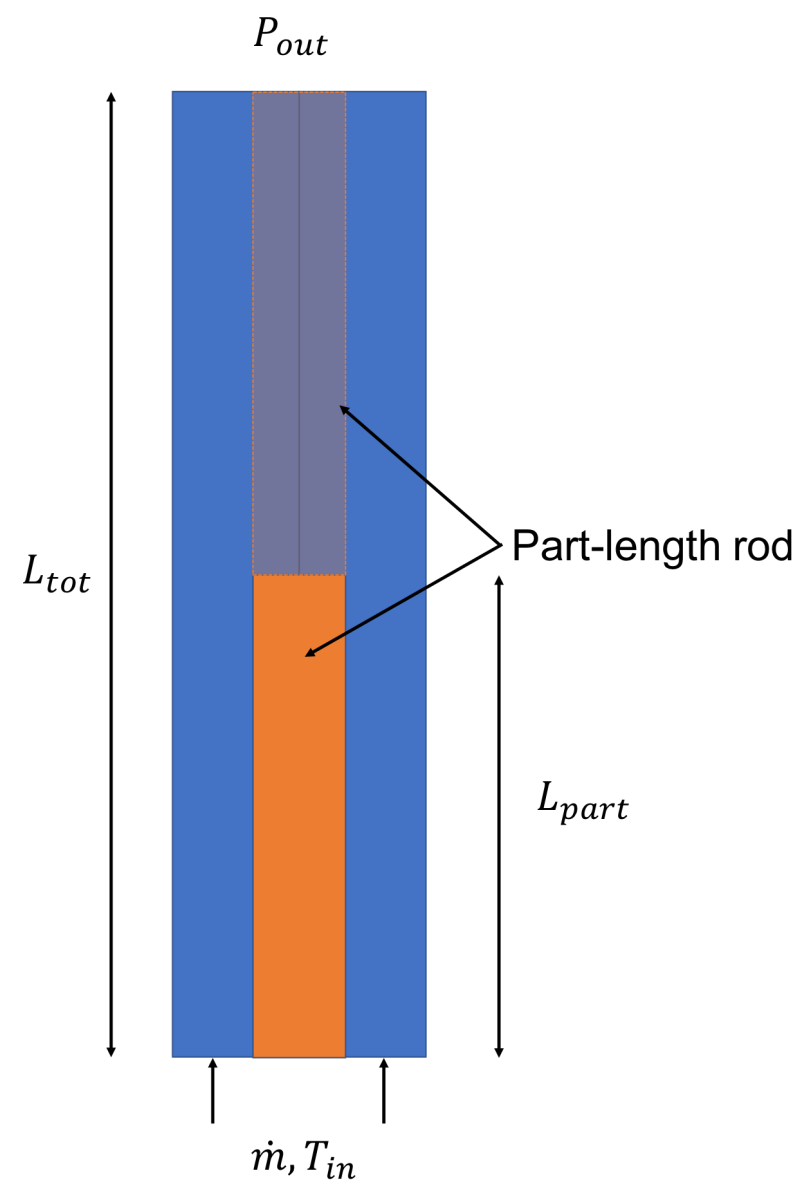

Figure 3. Example of flow expansion model geometry. 


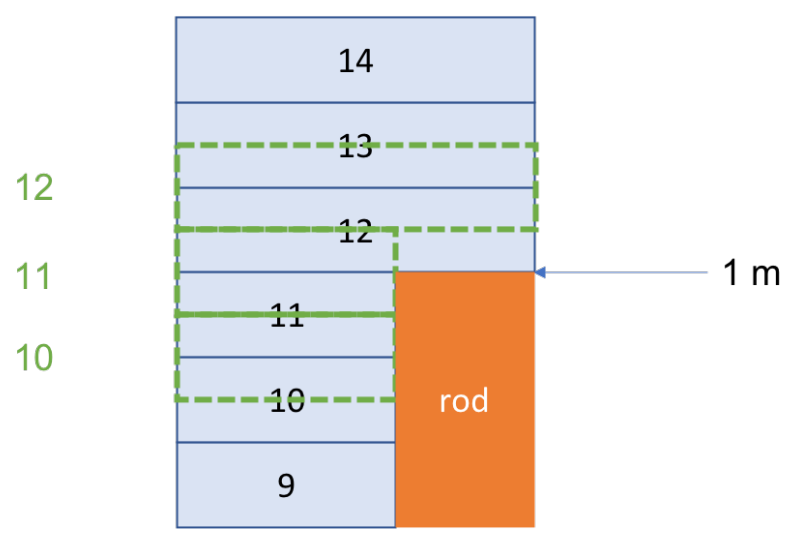

Figure 4. CTF staggered mesh for flow expansion test near point of expansion.

lower and upper sections of the model. The pressure change over the expansion will include effects of the form loss and the deceleration of the fluid. These effects are calculated as follows:

$$
\begin{aligned}
d P_{\text {loss }} & =\frac{1}{2} \rho k v_{\text {in }}^{2} \\
d P_{\text {acc }} & =\frac{1}{2} \rho\left(v_{\text {out }}^{2}-v_{\text {in }}^{2}\right)
\end{aligned}
$$

Equation (3) is the pressure drop due to form loss, and Eq. (4) is the pressure drop due to the slowing down of the fluid, where $k$ is the form loss coefficient.

The axial mesh is uniform, with each cell being $0.1 \mathrm{~m}$. Considering the geometry of the rod, the cross sectional area will increase by a factor of 1.2874 after the rod disappears, and the wetted perimeter will decrease by a factor of 0.71695 . The expansion is modeled using a set of area and wetted perimeter modification tables which apply the change in channel geometry at axial scalar and momentum level 12 in the model, which corresponds to $1 \mathrm{~m}$. The reason that the change is applied to level 12 can be seen in Figure 4, which shows the CTF staggered mesh around the expansion.

Each cell in CTF is $0.1 \mathrm{~m}$. Because the first cell is a ghost cell, it is not counted when placing the location of the expansion. Therefore, the top of CTF scalar cell 11 is located at $1.0 \mathrm{~m}$, which is the desired point of expansion. Scalar level 12 will be the first scalar cell where the area is opened. The momentum mesh index leads the scalar index by one because the first momentum level occurs at the top of the first scalar level. Momentum level 11 will retain the inlet area, which is consistent with the geometry being modeled. Momentum level 12 will be the first momentum level to have an expanded flow area. However, the form loss occurs at momentum cell 11, which is the top of the rod. To further simplify the analysis, the gravity is disabled in the CTF model, so gravitational head loss does not need to be considered.

The predicted and expected velocity profile in the model matches well, as indicated in Figure 5. The pressure drop is plotted as the total pressure drop per momentum cell. The analytical solution is calculated for each momentum cell individually. The momentum levels not affected by the form or expansion losses are simply the frictional loss using the velocity in that level. The form loss occurs at momentum level 11. The acceleration loss is spread over two momentum levels in CTF because the flow slows down over scalar 


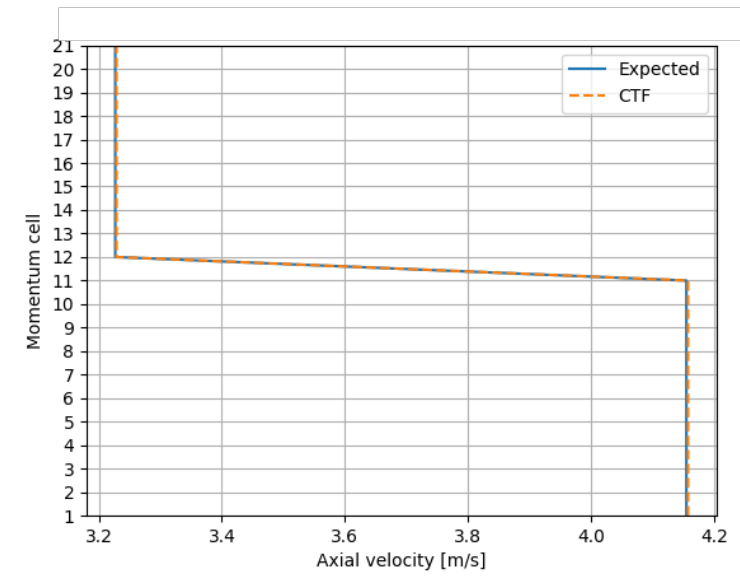

Figure 5. Comparison of expected and calculated velocities in the expansion verification test.

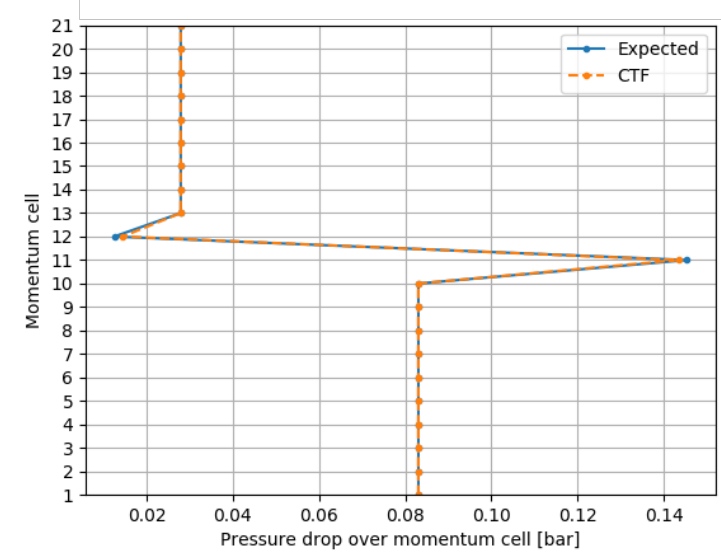

Figure 6. Comparison of expected and calculated pressures in the expansion verification test.

level 12, at the inlet value at the entrance of scalar level 12 and at the outlet value at the exit of level 12. Therefore, the deceleration drop occurring between scalar levels 11 and 13 is considered. For simplicity, half of the expected value is added to each momentum cell (11 and 12). The expected and predicted pressure drop over each cell is shown in Figure 6.

This problem shows that CTF can be used to model a flow expansion and to capture the deceleration and form loss components of pressure drop. This problem provides guidance on how to correctly place the form loss coefficient, expansion of area, and contraction of the wetted perimeter when modeling this geometry.

\subsubsection{Future work}

The testing performed on these approaches should be expanded in the future. The verification problem should be expanded to include the multisection approach to ensure that the same analytical solution can be 
obtained with both approaches. The tests that have been developed should be converted to two-phase flow in the annular mist-flow regime to ensure more realistic conditions. It must be verified that the two approaches obtain similar results when a film and droplets are involved to ensure that assumptions made in the table-based approach are valid. After these tests are performed, the results can be used to determine the best approach to implement into Xml2ctf. Once the selected approach is implemented, CTF will be able to model part-length rod geometry when a model is created from the VERAIn file.

\subsection{VERA-CS HDF5 file support for BWR geometry}

In the traditional CTF model, the code will have very little knowledge of how control volumes are placed in space. Rather, it will know the size of the control volumes and how they connect to the adjacent ones in the axial and lateral directions. When VERA is used to model LWRs, this information must be entered into CTF to write solution data to the VERA output format, which includes location information for each pin and channel in the model. During development for PWR geometry, a card group was added to the CTF input file that allows the user to specify pin and channel placement in the CTF model in the form of two-dimensional (2D) maps. These maps are then produced by Xml2ctf from the VERAIn common input file. An example is shown below.

$$
\begin{aligned}
& \text { *Card 17.4 - Rod Map } \\
& \begin{array}{llllllll}
-1 & -1 & -1 & -1 & -2 & -2 & -2 & -2
\end{array} \\
& \begin{array}{llllllll}
-1 & -1 & -1 & -1 & -2 & -2 & -2 & -2
\end{array} \\
& \begin{array}{llllllll}
-1 & -1 & 1 & 1 & 2 & 2 & 2 & 2
\end{array} \\
& \begin{array}{llllllll}
-1 & -1 & 1 & 1 & 2 & 2 & 2 & 2
\end{array} \\
& \begin{array}{llllllll}
-3 & -3 & 3 & 3 & 0 & 0 & 0 & 0
\end{array} \\
& \begin{array}{llllllll}
-3 & -3 & 3 & 3 & 0 & 0 & 0 & 0
\end{array} \\
& \begin{array}{llllllll}
-3 & -3 & 3 & 3 & 0 & 0 & 0 & 0
\end{array} \\
& \begin{array}{llllllll}
-3 & -3 & 3 & 3 & 0 & 0 & 0 & 0
\end{array} \\
& \text { * Card 17.4 - Channel Map } \\
& \begin{array}{lllllllll}
-1 & -1 & -1 & -1 & -1 & -2 & -2 & -2 & -2
\end{array} \\
& \begin{array}{lllllllll}
-1 & -1 & -1 & -1 & -1 & -2 & -2 & -2 & -2
\end{array} \\
& \begin{array}{lllllllll}
-1 & -1 & 0 & 1 & 1 & 2 & 0 & 2 & 2
\end{array} \\
& \begin{array}{lllllllll}
-1 & -1 & 1 & 1 & 1 & 2 & 2 & 2 & 2
\end{array} \\
& \begin{array}{lllllllll}
-1 & -1 & 1 & 1 & 1 & 2 & 2 & 2 & 2
\end{array} \\
& \begin{array}{lllllllll}
-3 & -3 & 3 & 3 & 3 & 0 & 0 & 0 & 0
\end{array} \\
& \begin{array}{lllllllll}
-3 & -3 & 0 & 3 & 3 & 0 & 0 & 0 & 0
\end{array} \\
& \begin{array}{lllllllll}
-3 & -3 & 3 & 3 & 3 & 0 & 0 & 0 & 0
\end{array} \\
& \begin{array}{lllllllll}
-3 & -3 & 3 & 3 & 3 & 0 & 0 & 0 & 0
\end{array} \\
& \text { \{assem map } \\
& \text { ** sym_opt nassem_rows nassem_cols } \\
& 5 \quad 3 \quad 3 \\
& \text { **Assembly Map } \\
& \begin{array}{lll}
0 & 3 & 0
\end{array} \\
& \begin{array}{lll}
2 & 1 & 2
\end{array} \\
& \begin{array}{lll}
0 & 3 & 0
\end{array}
\end{aligned}
$$


The rod map provides an assembly index for each pin in the model indicating the assembly to which each pin belongs. Similarly, the channel map specifies the assembly to which each channel belongs. The negative values indicate to CTF that the pin/channel exists in the assembly, but it is not solved by CTF since it is on the other side of a symmetry line in the model. Values of zero indicate that there is no pin or channel in that location. This particular model has large water rods, which is why the channel map has missing channels in the middle of each assembly. This is a small, made-up problem using $4 \times 4$ assemblies which is used for regression testing purposes.

The \{assem_map\} block specifies the symmetry option being used (full, quarter mirror, or quarter rotational), the dimensions of the core map (number of rows and columns of assemblies), and the layout of the assemblies in the core. Each index in the assembly map is a unique assembly index that is consistent with the indices specified in the rod Map and the channel map. The entire core is specified in this map. As previously indicated, some of the assemblies are on the other side of the symmetry line. In this case, the sister assembly index is used for specifying unsolved assemblies.

CTF currently has hard-coded assumptions that assume a PWR pattern (sea of rods) in which there will always be one more row and column of channels than there are rods. In the case of BWR geometry, there will be one extra row and column of channels for every assembly in the model. Therefore, this assumption must be relaxed. Furthermore, the RodMap and ChanMap classes in the code may need to be modified if there are any assumptions about how channels and rods are related.

Finally, one of the main uses of the RodMap and ChanMap classes is to organize solution data that are written to the VERA HDF5 file. Because of the PWR geometry assumption, data in the boundary channels are currently not being written correctly for BWR geometry. This must be fixed as part of this activity.

\subsection{Inlet orifice map}

An inlet orifice map is used to specify loss coefficients at the inlet of each assembly in the model. Because the center of the core will be more voided than the periphery of the core, the pressure drop and flow resistance will be higher in the center. This will cause water entering the core to prefer the periphery assemblies and will choke flow to the high power regions. To counter this effect, the core plate can include assembly inlet orifices that are sized differently to better balance flow delivery.

There is currently no straightforward method for entering this information into the VERAIn common input file. As such, the ability to enter a map will be added to the CORE block of the input file; the map will have the same dimensions as the core map, and each value will provide a form loss coefficient.

In addition to the core plate losses, which do not change from cycle to cycle, the assembly itself can have different inlet and outlet form losses which will affect the overall flow distribution in the core. To capture this, the ASSEMBLY block will be modified to include an inlet form loss and an outlet form loss. This information will stay with the assembly as it is shuffled around the core.

Xml2ctf will be modified to read these new inputs and will transfer these form loss coefficients to the individual channels that comprise the assemblies to which they belong. The form loss coefficients will be uniform for all of the channels in the assembly to which the loss is applied. Note that the form loss coefficients must be added to the second momentum level in CTF, because when a mass flow rate inlet boundary condition is applied, any losses will not be included in the pressure calculation. This should not 
have any significant impact on the effect of pressure drop in the assembly or to the total mass flow rate delivery to that assembly.

\subsection{Expansion of Xml2ctf regression testing}

Xml2ctf converts the VERAIn file to the CTF input deck. The Xml2ctf regression testing matrix for BWR geometry is currently limited. A summary of the test cases that are included is provided below:

- Mock Peach Bottom $8 \times 8$ assembly, including a channel box with rounded corners and guide tubes.

- $8 \times 8$ bundle with solid stainless steel rods

- $8 \times 8$ bundle with a single large water rod

- Model of $48 \times 8$ assemblies of two different types, to be run in serial

- Model of $48 \times 8$ assemblies of two different types, to be run in parallel

- $3 \times 3$ lattice model with channel box used to demonstrate that odd-lattice assemblies can be modeled

- Model with fuel rod that has no gap between pellet and clad to protect the ability to model fuel rods without gaps

This test matrix should be expanded to cover all geometries of interest. The most effective approach would be for the Virtual Environment for Reactor Applications (VERA) Applications Focus Area to create a suite of VERAIn models representing cases that need to be run and then deliver this to the CTF development team so that Xml2ctf can be expanded as needed, with each model being added as a regression test to protect all added features.

\section{MODELING IMPROVEMENTS}

\subsection{Bypass flow modeling}

The typical approach for modeling bypass flow in BWRs involves using pre-generated tables that are a function of core power and core flow. This is the initial approach to be used in the core simulator. However, modeling the bypass explicitly would allow for a more predictive capability that could capture the effect of heat transfer to the bypass region and any voiding that may occur. The challenging aspect of modeling the bypass involves correctly characterizing the local losses in the model of that region. It should be possible to set up the channel system in CTF to represent the bypass region as long as losses can be adequately represented. This work task, which will be led by North Carolina State University (NCSU), will analyze explicit modeling of the bypass region using CTF and will characterize the effects of heat transfer communication with the active core region. This task will also include analysis of figures of merit such as bypass voiding. 


\subsection{Two-phase closure model improvements}

$\mathrm{CTF}$ has a fairly extensive validation matrix, which is documented in its V\&V manual [15]. This matrix was designed using a top-down approach that (1) considers the intended applications of CTF, (2) uses the intended applications to generate high-level requirements, (3) includes verification tests designed to test features and separate effects models in support of those requirements, and (4) seeks out open separate effects and integral experimental data to test the accuracy of code models and numerical methods.

The intended CTF applications are as follows:

1. normal PWR operating behavior

2. normal BWR operating behavior

3. DNB analysis of PWRs

4. CIPS analysis of PWRs

5. reactivity insertion accident (RIA) analysis in PWRs

The high-level requirements developed from the list of applications is provided below:

1. Single-phase convective heat transfer

2. Subcooled nucleate boiling heat transfer

3. Near wall vapor generation

4. Single-phase form loss

5. Two-phase form loss

6. Single-phase wall shear

7. Two-phase wall shear

8. Spacer grid heat transfer enhancement

9. Spacer grid turbulent kinetic energy (TKE) enhancement

10. Single-phase turbulent mixing
11. Two-phase turbulent mixing

12. Pressure directed cross flow

13. Nucleate boiling heat transfer

14. Void drift

15. Droplet entrainment and de-entrainment

16. Small bubble interfacial drag and implicit heat transfer

17. Large bubble interfacial drag and implicit heat transfer

18. Annular mist interfacial drag and implicit heat transfer

19. Critical heat flux

As indicated in the list, BWR modeling applications are included. Several two-phase tests were added to the validation matrix to support these requirements. The test sources and the requirements they test are summarized in Table 1.

As indicated in the table, there is generally good coverage of the requirements. During two-phase validation efforts, it was found that CTF tends to over-predict void content in lower void flow regimes (i.e., small bubble and large bubble). An example is provided in Figure 7, which shows the bundle-average outlet void predicted by CTF for the BFBT void distribution cases compared to the experimental results. As shown in the figure, there is a clear bias in void being over-predicted in small- and large-bubble flow 
Table 1. Summary of two-phase validation tests in CTF test matrix and requirements satisfied

\begin{tabular}{|c|c|}
\hline Dataset & Requirement \\
\hline PSBT Series 1-4 (channel) [13] & $2,3,16,17$ \\
\hline PSBT Series 5-7 (bundle) [13] & $2,3,11,14,16,17$ \\
\hline BFBT P6 pressure drop [10] & $5,7,16,17,18$ \\
\hline BFBT void distribution [10] & $3,11,14,16,17,18$ \\
\hline RISO tube [17] & $7,15,16,17,18$ \\
\hline CE $5 \times 5$ [8] & $1,2,10,11,12,13$ \\
\hline $\mathrm{GE} 3 \times 3[11]$ & $3,11,12,14$ \\
\hline Harwell [3] & 19 \\
\hline
\end{tabular}

regimes. Figure 8 provides void prediction results for the PSBT single-channel Series 1 tests, which show a similar trend, although not as extreme.

Using a two-fluid modeling approach for two-phase flow relies on interfacial drag closure models for determining phase slip, which is one of the primary parameters required for predicting void content. This over-prediction may point to inaccurate prediction of interfacial drag in specific flow regimes recognized by CTF. Another important parameter is the prediction of vapor generation at the wall due to subcooled and saturated boiling. Rather than using an onset of nucleate boiling model, CTF predicts boiling as soon as the rod surface temperature rises above the local saturation temperature, and it relies on a near-wall condensation model to condense vapor back to liquid when the heat transfer regime is subcooled boiling. This boiling closure model may need additional validation and calibration.

In addition to the issues with over-prediction of void, it has also been observed that CTF demonstrates a clear bias in prediction of two-phase pressure drop in the annular mist flow regime. Figure 9 shows the measured vs. the predicted pressure drop for the RISO tube tests.

Previous work has been performed to incorporate the more physically correct Lane model, which exhibits much better prediction of two-phase pressure drop, as shown in Figure 10. However, a wider assessment of this model was never performed for the other validation cases, and it has been observed to exhibit numerical convergence issues as implemented into the code. As two-phase pressure drop is a function of the interfacial friction and wall shear, prediction of void and two-phase pressure drop must be considered while making improvements to the closure models.

As these flow regimes will be encountered when modeling BWRs, work will be performed to improve on void prediction by CTF. The following initial steps have already been taken:

- Perform a brief review of other available models for subcooled boiling

- Begin a literary search for additional two-phase data that can be added to the validation matrix

- Begin adding new tests to the validation matrix

- Develop an automated validation test matrix driver utility

- Perform initial refactoring of the CTF two-phase closure models

These objectives are explained further in the sections that follow. Based on the findings in the present 


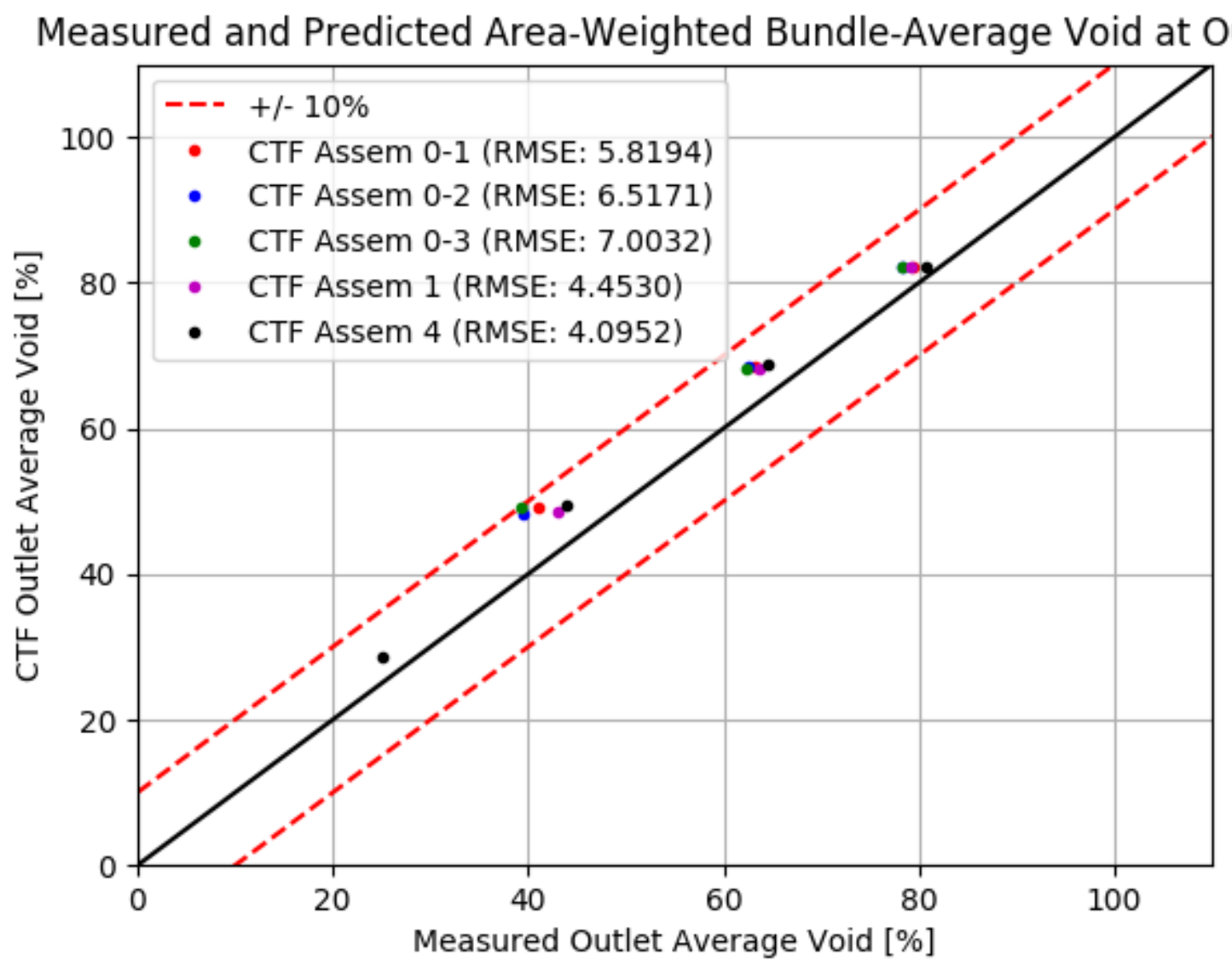

Figure 7. Comparison of CTF predicted average outlet void and measurements for BFBT void distribution cases. 


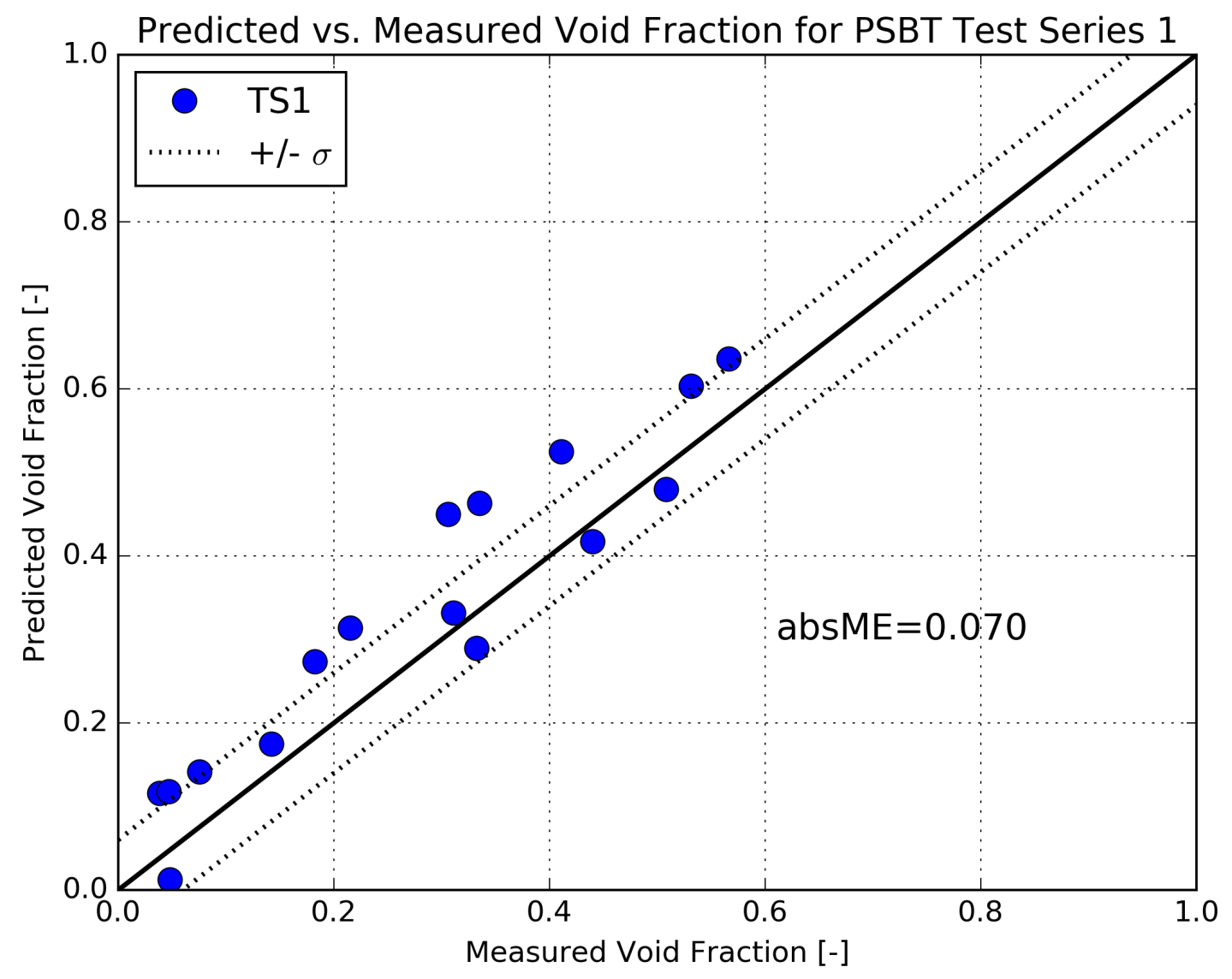

Figure 8. Comparison of CTF predictions of void to measurements in the PSBT single-channel, Series 1 tests. 


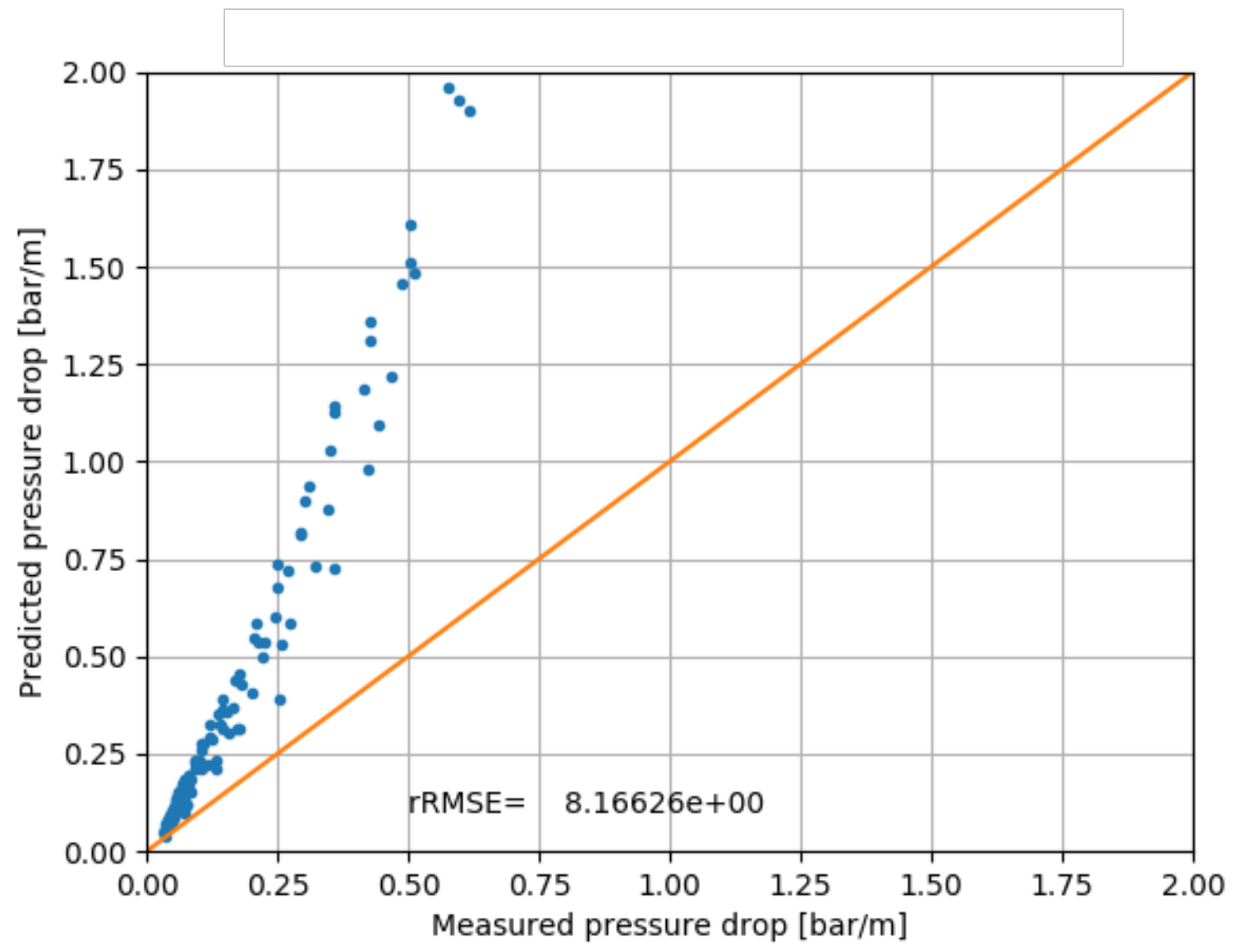

Figure 9. Two-phase pressure drop prediction of CTF for RISO tube tests compared to experimental results. 


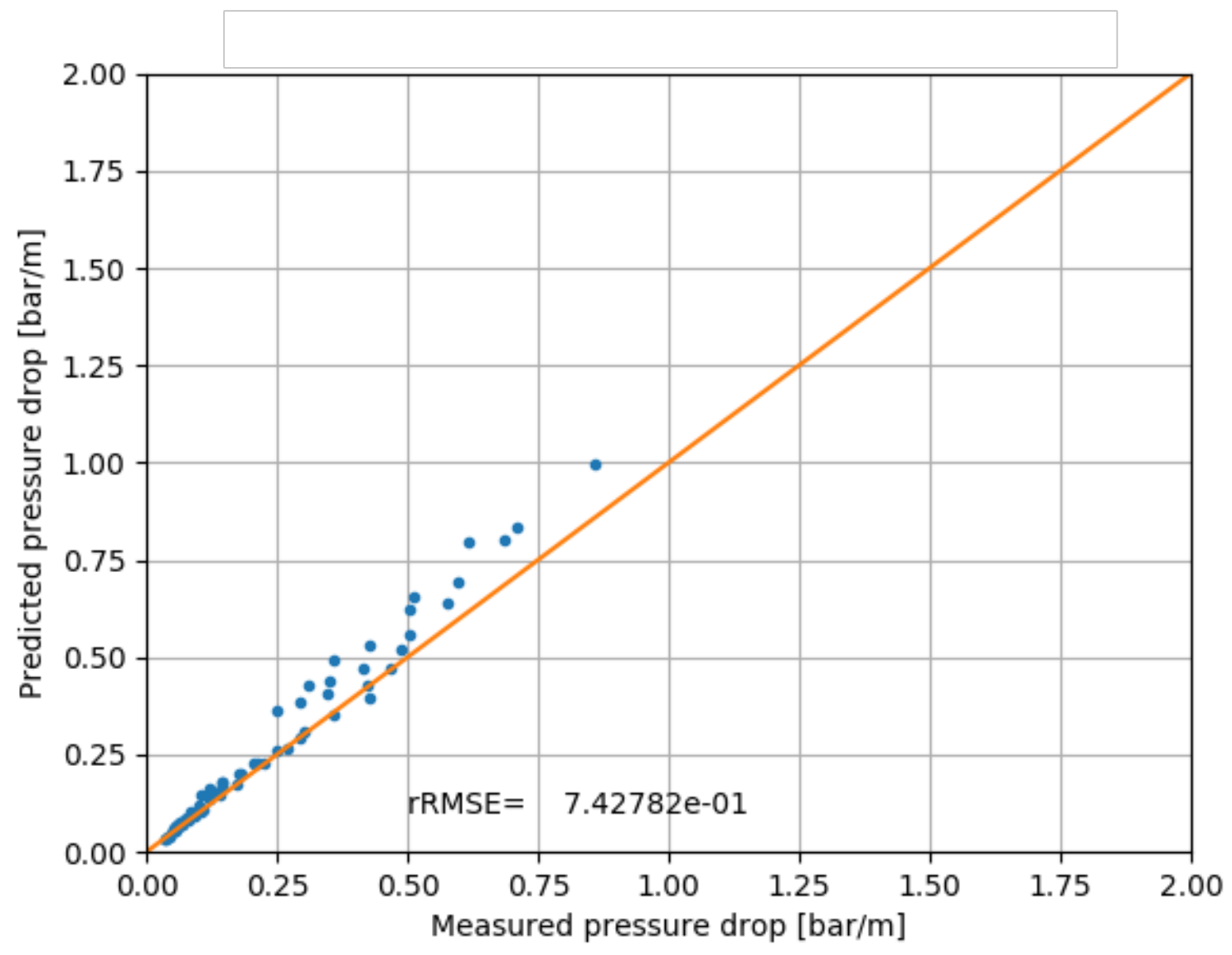

Figure 10. Two-phase pressure drop prediction of CTF for RISO tube tests compared to experimental results using the Lane closure models for annular-mist flow. 
work, a path is established for making improvements to the closure models.

\subsubsection{Boiling model options}

Other modeling choices were considered by reviewing approaches in other common two-phase flow modeling codes.

3.2.1.1 VIPRE-01 VIPRE-01 (VIPRE) [16] is a drift-flux code, meaning that only one set of equations is solved for each of the governing equations (mass, momentum, and energy) rather than solving separate equations for each phase. The fluid is considered to be a two-phase mixture, and void will be calculated from the mixture energy. To improve on the accuracy of this determination, the slip between the two phases is considered in the calculation, as it is known to impact the fluid's void content.

VIPRE, like CTF, must consider the solid surface temperature when boiling is present, as well as the void during subcooled boiling. VIPRE uses a heat transfer coefficient (HTC)-based model for predicting the heat flux (Equation 5).

$$
q "=H\left(T_{w}-T_{b}\right)
$$

Like CTF, the entire boiling curve is considered, with separate models being used to calculate $H$ for single-phase convection, nucleate boiling, transition boiling, and film boiling regions. To determine the transition point, the max of the single-phase and boiling HTCs is taken, and the larger one determines the heat transfer regime. The HTC used in Equation 5 will be calculated as the sum of the two HTCs. The same correlation (either Thom or Chen) is used for both subcooled and saturated nucleate boiling. CTF works in essentially the same manner when it comes to determination of the HTC in single-phase and boiling regions. The same boiling models are available in CTF and VIPRE.

To determine the void in subcooled boiling, VIPRE uses a relationship between flow quality, slip, and void, as shown in Equation 6,

$$
\alpha=\frac{x v_{g}}{(1-x) v_{f} S+x v_{g}}
$$

where $\alpha$ is void, $x$ is flow quality, $v$ is the specific volume, $f$ and $g$ subscripts represent saturated liquid and vapor, respectively, and $S$ is the ratio of vapor and liquid velocity. The slip ratio can be entered as a constant to VIPRE, or it can be calculated by the code using an empirical correlation. The other parameter that must be calculated is the flow quality. As VIPRE does not model the phases individually, their individual velocities are not known explicitly. Rather, VIPRE will calculate the equilibrium quality, $x_{e}$, of the mixture. The flow quality is determined using one of two profile-fit models, which both are a function of equilibrium quality and the equilibrium quality at the point where bubbles depart. This approach for determining subcooled void production is very different from the approach used in CTF, which is largely because CTF is a two-fluid code.

The approach is fully documented in the CTF Theory Manual [14], and a brief overview is provided here. As CTF solves mass and energy equations for both phases, it determines the split in the boiling heat flux, 


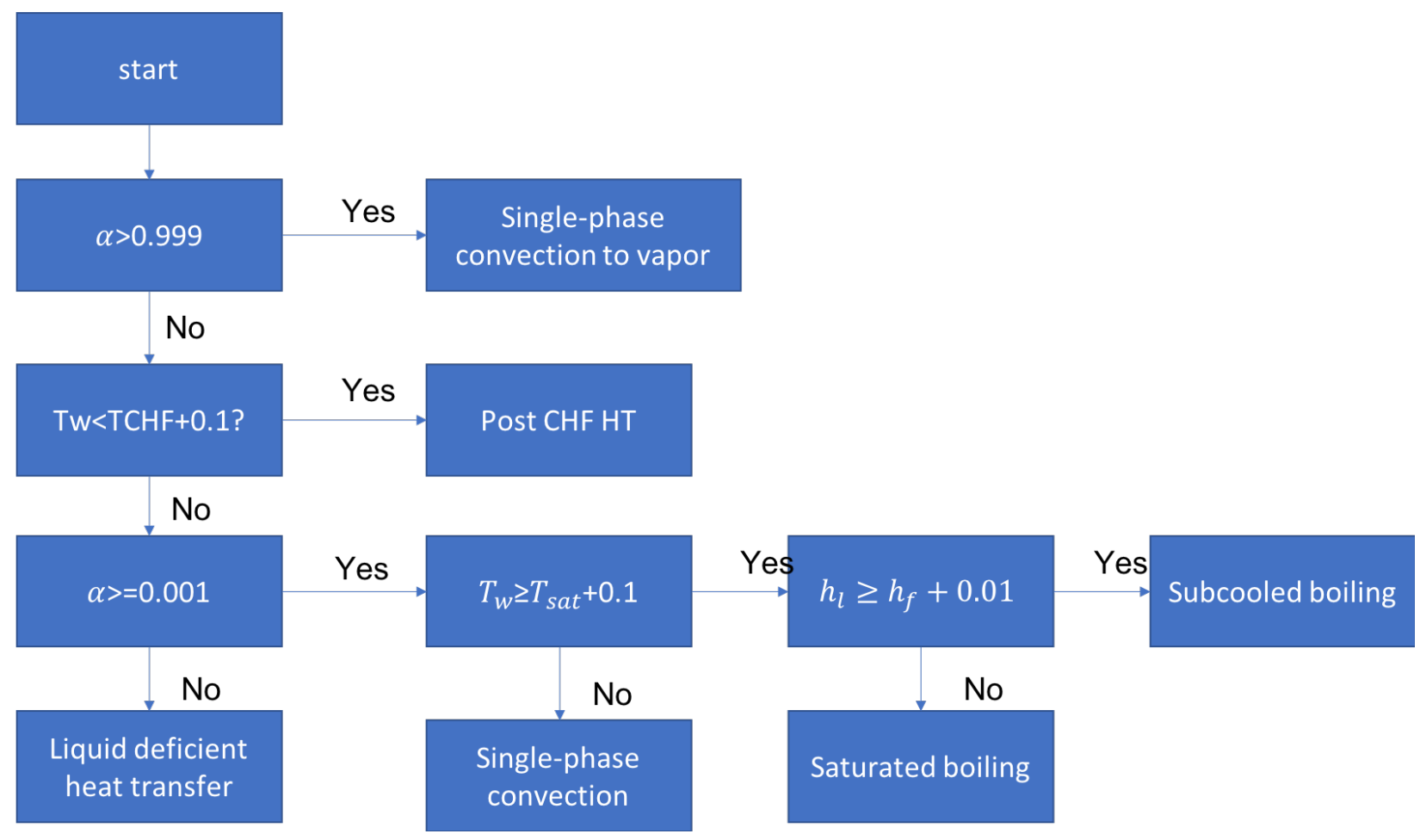

Figure 11. CTF decision matrix for determining heat transfer regime (emphasis on selection of boiling regime).

with one part delivering energy to the fluid, and one delivering the energy to the vapor phase. In subcooled boiling, vapor bubbles may collapse before detaching, or they may detach and condense after leaving the superheated film near the wall. CTF determines the heat transfer regime based on the logic shown in Figure 11.

The post-critical heat flux (CHF) regimes are not detailed in Figure 11. In the subcooled boiling regime, CTF calculates a subcooled boiling factor, $F$ that is between zero and one, which represents the fraction of boiling heat transfer resulting in bubble generation that remains in the vapor phase. This is calculated as shown in Equation 7:

$$
F=\frac{q "{ }_{\mathrm{nb}}-q "{ }_{\mathrm{cw}}}{q "{ }_{\mathrm{nb}}} \epsilon
$$

where $q "{ }_{n b}$ is the total heat flux calculated by the nucleate boiling model (Chen or Thom), epsilon is a factor that accounts for the enhanced heat transfer due to subcooled water being pumped into the superheated near-wall film due to bubbles leaving the surface (it will be between zero and one, reducing the amount of bubbles remaining in the vapor phase), and and $q "{ }_{\mathrm{cw}}$ is the amount of heat flux lost to near wall condensation. This term is formulated as follows:

$$
q "{ }_{\mathrm{cw}}=\max \left(0.0, q{ }_{\mathrm{hn}}-q{ }^{\prime \mathrm{db}}\right) .
$$


The $q$ " hn heat flux is calculated using the Hancox-Nicoll near-wall condensation model, which is meant to calculate the total heat flux during subcooled boiling. All bubbles condense at the heat flux predicted by this model. The single-phase heat flux calculated by Dittus-Boelter is removed from this term. The net amount is therefore the amount of heat flux that will condense back to liquid. This is subtracted from the total heat flux to determine how much of the vapor remains in the vapor phase. Note that this term is only calculated for subcooled boiling and will be zero for nucleate boiling. Based on this formulation, it is clear that the accuracy and applicability of Hancox-Nicoll to conditions modeled by CTF is crucial for correcting the prediction of bulk void in the subcooled boiling region. The latent heat factor, $F$, is used later by CTF to determine the vapor generation rate (mass transferred from the liquid to the vapor mass equation).

3.2.1.2 TRACE TRACE [1] is a two-fluid code like CTF, so it must consider how energy leaving the wall is partitioned between the liquid and vapor phases.

Like CTF, TRACE considers the single-phase and boiling heat transfer regimes of the boiling curve. Unlike VIPRE and CTF, TRACE uses an explicit onset of nucleate boiling criterion to determine when the regime transition takes place. As discussed above, VIPRE takes the maximum of the HTCs to determine the correct regime, and CTF switches to boiling as soon as the rod surface temperature rises above the local saturation point. TRACE uses the model of Basu to determine at which wall superheat (the difference between actual wall temperature and local saturation temperature) is required to switch to boiling heat transfer. After the heat regime is determined to be boiling, an additive approach is used to combine forced convection and boiling heat fluxes. Unlike CTF and VIPRE, which both simply add the two heat fluxes, TRACE uses a super-position method developed by Steiner and Taborek, as shown below:

$$
q "{ }_{\mathrm{NB}}=\left[q_{\mathrm{FC}}^{\prime 3}+q_{\mathrm{PB}}\right]^{1 / 3} .
$$

The model of Gorenflo is used as the pool boiling model indicated by $q$ "Рв. The forced convective heat flux is represented by $q$ "FC. This equation is actually modified slightly to prevent a discontinuity at the point of onset of nucleate boiling (ONB) by removing the fully developed boiling heat flux at the point of boiling initiation, $q$ "вI", as indicated below:

$$
q "{ }_{\mathrm{NB}}=\left[q_{\mathrm{FC}}, 3+\left(q{ }_{\mathrm{PB}}-q{ }_{\mathrm{BI}}\right)^{3}\right]^{1 / 3},
$$

where $q$ " ${ }_{\mathrm{BI}}$ is simply $q$ " ${ }_{\mathrm{PB}}\left(T_{\mathrm{ONB}}\right)$. This heat flux is then used to calculate the HTC and, thus, to calculate the wall temperature.

Similar to CTF, TRACE uses a subcooled boiling factor to determine the amount of boiling heat flux that results in vapor generation. Specifically, the wall vapor generation rate is formulated as follows:

$$
\Gamma_{\mathrm{sub}}=\frac{f_{\mathrm{sub}}\left(q{ }_{\mathrm{NB}}-q{ }^{\prime}{ }_{\mathrm{FC}}\right) A_{w}^{\prime \prime \prime}}{h_{g}-h_{l}},
$$

where $f_{\text {sub }}$ is the subcooled boiling factor. It is multiplied by the total boiling heat flux, which in TRACE is assumed to be the total boiling heat flux minus the forced convective heat flux. This assumption is specifically stating that forced boiling heat flux is a combination of pool boiling effects and forced convection effects. $A_{w}^{\prime \prime \prime}$ is the wall area per unit volume, and the denominator is the enthalpy rise required 
to convert subcooled liquid to vapor. Unlike CTF, which uses the Hancox-Nicoll model to estimate the heat flux leading to vapor generation, TRACE uses the liquid enthalpy required for bubble detachment, as shown below:

$$
f_{\text {sub }}=\max \left(0, \frac{h_{l}-h_{l d}}{h_{f}-h_{l d}}\right)
$$

where $h_{l d}$ is the liquid enthalpy at which bubbles begin to detach. As the liquid enthalpy reaches saturation, the factor goes to one, and all boiling heat flux results in vapor generation. If the liquid enthalpy is below the threshold value, then the factor becomes zero, and none of the bubbles detach.

When bubbles detach, they may still condense in the bulk liquid. However, TRACE assumes that its interfacial heat transfer model will be adequate in causing this condensation to occur. Note that CTF also has an interfacial heat transfer model that will cause vapor to condense back to liquid when the liquid is subcooled.

3.2.1.3 THERMIT-2 The THERMIT- 2 code is another two-fluid code developed by MIT for subchannel analysis [9].

Similar to TRACE, THERMIT-2 uses the concept of a bubble detachment temperature to determine the amount of vapor generation in subcooled boiling. In fact, the factor is posed almost exactly as Equation 12, with the only difference being that it is posed in terms of temperature in THERMIT-2 instead of enthalpy. The difference from TRACE is that the Ahmad model is used to predict the bubble detachment temperature in THERMIT-2, whereas the Saha and Zuber model is used by TRACE.

The total vapor generation rate in saturated boiling will be as follows.

$$
\Gamma=\frac{q " w}{h_{f} g}
$$

Note that the THERMIT-2 manual seems to indicate that the wall heat transfer in boiling flow is calculated from the boiling model only. In other words, there is no superposition of forced convection and boiling heat transfer effects as in the other three codes reviewed thus far. This previous equation seems to agree with that finding, because the total heat flux is used to determine vapor generation (rather than subtracting the forced convection component first). Physically, the heat flux predicted by these models will not be solely due to vapor generation, as some energy is also used to heat up the subcooled liquid. The Chen and Thom models are available for predicting the boiling heat flux. The subcooled boiling factor will be multiplied by this total vapor generation rate to determine the amount of vapor generation in subcooled boiling.

Similar to TRACE, THERMIT-2 relies on interfacial heat transfer to account for the condensation that occurs in the subcooled bulk. Ahmad's paper is referenced for determination of the interfacial area and HTCs for this region. 


\subsubsection{Path Forward}

With a preliminary assessment of the approaches of VIPRE, TRACE, THERMIT-2, and CTF complete, a path forward for improving the CTF two-phase closure models is proposed.

Predicting two-phase parameters like void and two-phase pressure drop requires correct prediction of a number of separate effects like vapor generation from wall boiling, interfacial drag, and wall drag. Because consideration of all effects simultaneously adds complexity to the process of improving the closure models, the approach will be to separate importance of effects by focusing on limited operating regions. Two parameters must be correctly predicted when considering the boiling model. First, the heat transfer coefficient must be calculated so that it leads to the correct rod surface temperature. Experiments will be added to the test matrix to ensure that this is the case. Second, the vapor generation rate must lead to the correct addition to the vapor phase. In saturated boiling, the mass transfer rate is simply the heat flux divided by the latent heat of vaporization, but in subcooled boiling, a large portion of the vapor will either not detach from the wall at all or will condense after reaching the bulk.

CTF includes a near-wall condensation model (Hancox-Nicoll) to account for this, but its adequacy in correctly accounting for this effect is not clear when reading the original Hancox-Nicoll paper, and it is not clear that its use in the CTF model is in line with the actual physics. The other three codes all use a similar approach of considering the bubble detachment temperature, which is in line with what physically happens in the subcooled boiling process. Some benchmarking has previously been performed with VIPRE [21] and TRACE, and the results show overall better prediction of void and pressure drop in pre-CHF flow regimes using those codes. It is not clear if this is due to the formulation of the subcooled boiling model, the interfacial drag model, or both. Both VIPRE and TRACE use a drift-flux-based model to predict phase slip. (TRACE uses the drift-flux approximation to essentially back-calculate the interfacial drag that links the liquid and vapor phases.) However, considering that CTF seems to disagree with onset of significant void (OSV) when compared to experiment and other codes, the subcooled boiling model is a good candidate for examination. Consideration will be given to switching the CTF formulation to a similar approach that considers the bubble detachment temperature. To properly assess this model, the work should focus on subcooled experiments in which boiling is present and should ensure that CTF is predicting the correct void content for these cases, and if not, then the model must be recalibrated.

After correcting the subcooled boiling model, attention can be directed at cases with low void in which wall-boiling starts to contribute to the bulk void. In low-void cases at higher mass fluxes, the interfacial drag should be relatively easy to remove from consideration because it is expected that there will be essentially no slip between the phases for these conditions. Low-void experiments can be binned by flow conditions, and a sensitivity study can be performed on the interfacial drag to ensure that this is the case. There should be an upper limit at which further increases to the interfacial drag do not affect predicted void, although reducing it may cause void prediction to increase. For cases in which the interfacial drag is certain, all void should be expected to come from near-wall generation; this can be used to expand on the boiling model calibration. Finally, attention can then be given to cases in which interfacial drag is expected to play an important part and the model can be calibrated. 


\subsubsection{Expansion of the testing matrix}

The plan for improving the two-phase closure models in CTF will require more data in the validation matrix. A literary search for possible two-phase data that would be useful to add to the validation matrix for improving on the assessment of CTF is in process. Possible candidates are summarized as follows:

1. Bennett tests [3]: These tests are already in the CTF validation matrix, but their scope of analysis can be expanded. The tests ran water at high pressure upwards through a tube that was electrically heated to the point at which the liquid boiled off and the tube dried out. Dry-out was detected by thermocouples that were attached axially along the outside of the tube. The tests were only used to validate the CTF dry-out prediction, but the entire temperature profile can be compared to CTF predictions to validate the boiling heat transfer model, in addition to the CHF model.

2. Void profile tests [4]: These tests involved running water through a rectangular channel at BWR conditions. The axial void profile was measured in roughly $6 \mathrm{~cm}$ increments using a gamma-ray attenuation technique. Despite the data being old, good agreement was found with the subcooled boiling model implemented in THERMIT-2 [9], so similarly good agreement with the CTF boiling model is expected.

3. Mass flow and enthalpy distribution in PELCO-S [7]: This $4 \times 4$ rod bundle was run using steam/water at BWR operating conditions. Outlet mass flux and enthalpy distribution were measured; this is very similar to the measurement approach and data extracted in the GE $3 \times 3$ facility [11]. The data would not add anything new to the matrix, but they would add more data from an independent source. This may be more useful for calibration of the two-phase turbulent mixing model, as no void measurements were made.

4. DEBORA tests [19]: These tests are fairly recent tube boiling tests in which very detailed radial void distribution measurements were made at the outlet of the test section. A drawback of these tests is that R-12 was used as the working fluid, and while CTF can take user-defined fluid properties for subcooled liquid, this capability would need to be extended to two-phase properties for these tests to be easily modeled.

5. NESTOR tests [18]: The NESTOR tests are steam/water tests that were performed under prototypical PWR operating conditions in a $5 \times 5$ rod bundle using realistic mixing vane grids. Very detailed rod surface temperature measurements were made, which would allow for validation of the convection and boiling heat transfer models.

6. WALT loop [5]: The Westinghouse Advanced Loop Tester (WALT) was run at PWR conditions to generate data for crud models. Several clean-rod cases were run that included subcooled boiling conditions; these cases can be used to validate the CTF heat transfer model.

7. Rouhani tests [12]: The Rouhani tests involve steam/water up-flow in an annular test section. Tests were run at low-to-high pressure, and void measurements were made at a fixed location near the test section's outlet. This series included a large number of tests run at subcooled and saturated boiling conditions. The test cases were run using heavy water, so it may be necessary to change the fluid properties to model these cases.

The Bartolomei [6] tests were high-pressure tests that have been used extensively for computational fluid dynamics (CFD) validation in CASL, so they have already been added to the CTF validation matrix and 
Table 2. Ranges of operating conditions for the Bartolomei tests

\begin{tabular}{lrrr}
\hline Parameter & Min. value & Max. value & Unit \\
\hline Pressure & 15 & 148 & bar \\
Mass flux & 405 & 2,100 & $\mathrm{~kg} / \mathrm{m}^{2}-\mathrm{s}$ \\
Heat flux & 420 & 2,210 & $\mathrm{KW} / \mathrm{m}^{2}$ \\
Inlet subcooling & 11 & 140 & $\mathrm{deg} \mathrm{C}$ \\
\hline
\end{tabular}

benchmarked against STAR-CCM+ as part of this work. The STAR-CCM+ results are preliminary and can be found in [20].

\subsubsection{Bartolomei tests}

The Bartolomei experimental facility and tests are described in two articles by Bartolomei et al. [2], [6], which describe 38 tests which were modeled with two different base geometries: a $15.4 \mathrm{~mm}$ vertical tube with a fixed length of $2000.0 \mathrm{~mm}$, and a $20 \mathrm{~mm}$ vertical tube with varying lengths ranging from $800.0 \mathrm{~mm}$ and $1500.0 \mathrm{~mm}$. The range of operating conditions is shown in Table 2. These tests involve upwards flow through a vertical cylindrical pipe, with a constant applied heat flux over the entire pipe. Void fraction measurements are not available for 11 of the 38 cases, so only 27 cases are included. Of these, wall temperature and liquid temperature measurements are available for Case 1, in addition to cross sectional void fraction measurements at different axial locations, which are provided for all 27 cases.

The system pressure and inlet liquid flow rate were measured using a manometer and a differential manometer-flowmeter. Flow temperatures at the inlet and outlet of the experimental section were measured using chromel-copel thermocouples. Flow temperature measurements are also available for Case 1 along the flow axis, as well as radial temperature profile measurements obtained by traversing the thermocouple at several points over the cross section of the flow. The temperature of the tube's outer wall was also measured using the traversing thermocouples. The mean calometric temperature measurement is used for the Case 1 validation study. Temperature measurements of the external surface of the heated wall tube are also available but are not used in the validation study. Heat flux is determined by measuring the electrical power supplied to the heaters. According to the study's authors, for Cases 13-38, the maximum relative errors did not exceed 0.01 for pressure, 0.02 for mass velocity, and 0.03 for heat flux, and the maximum absolute error of temperature did not exceed $1 \mathrm{~K}$. The mean true vapor content (void fraction) was determined by penetrating gamma radiation from a ${ }^{170} \mathrm{Tm}$ source. Further details on the void fraction measurement, including the calibration process are given in Bartolomei's articles [2], [6]. The authors mention that the maximum absolute errors in the void fraction measurements do not exceed 0.04 for Cases 13-38.

Experimental data used for this study include 27 conditions from the two tubular geometry test sections. A script is used to generate the CTF input files automatically for Cases 13-38, whereas the input file for Case 1 is manually generated. The CTF models are created using internal flow in a single channel, with the inlet mass flux and inlet temperature used to set the inlet boundary conditions, and system pressure is used for the outlet boundary condition. Uniform heat flux is provided at the outer heater's wall surface, with the linear heat rate calculated to correspond to the experimental heat flux at the inner heater's surface/outer internal tube surface. The $15.4 \mathrm{~mm}$ and $12.0 \mathrm{~mm}$ diameter test sections are both divided into uniformly 


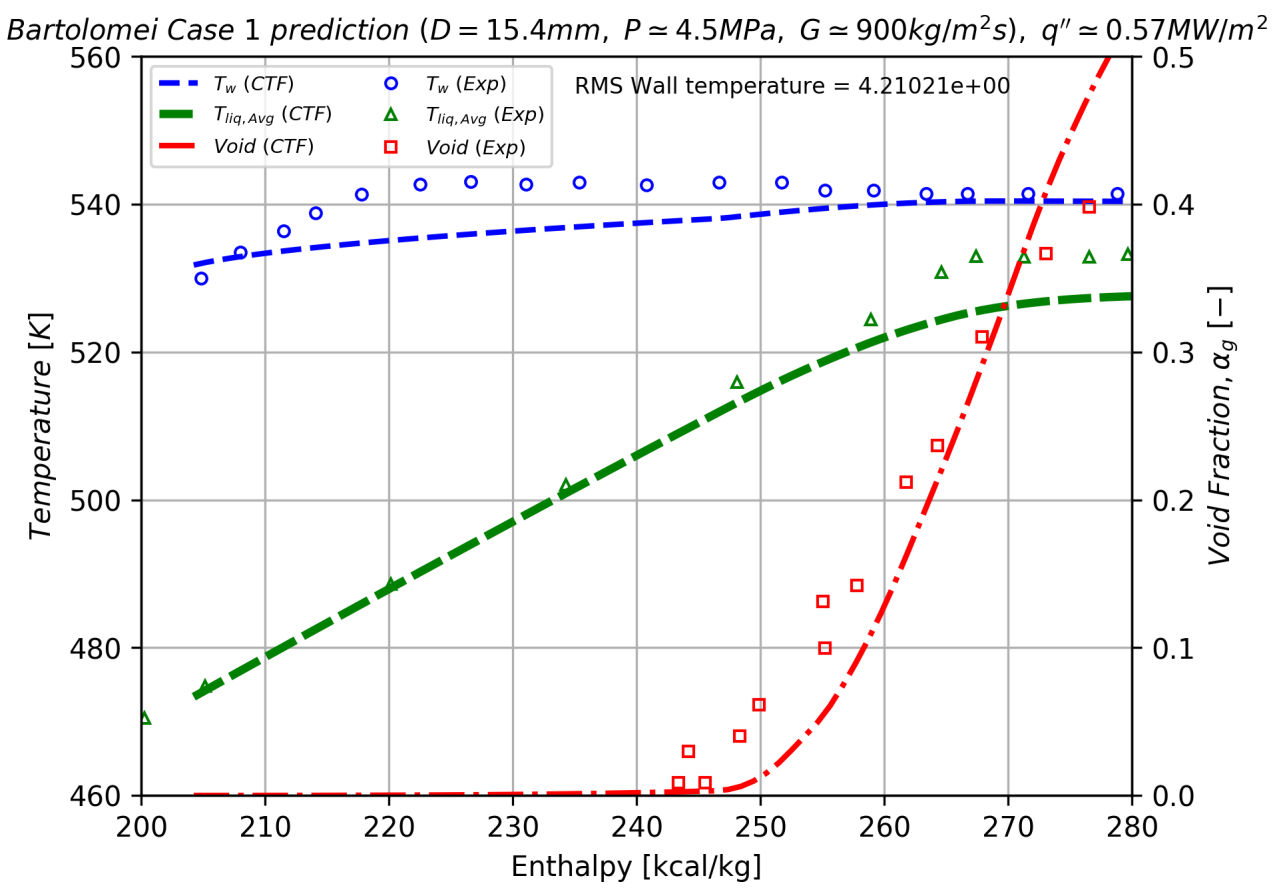

Figure 12. Comparison of CTF and experimental data of wall temperature, mean liquid temperature, and void fraction for Case 1.

spaced axial nodes with a nodal size of $25.0 \mathrm{~mm}$ - roughly twice the hydraulic diameter-which is consistent with the typically recommended mesh size for CTF calculations. Since the exact tube lengths are unknown for cases 13-38, a fixed tube length of $1.5 \mathrm{~m}$ is used which corresponds to a total of 60 nodes.

The total number of nodes for Case 1 is 80 .

The results of Case 1 are shown in Figure 12. CTF captures the overall trend in the axial void development and liquid temperature profile very well. However, CTF predicts the location of ONB at the very first node in comparison to the experimental data, which predict ONB further downstream. Furthermore, the liquid temperature measurement close to the exit exceeds the saturation temperature according to the IF97 steam-water properties used in CTF. The experimental void fraction plateaus at the exit, whereas the CTF-predicted void fraction continues to rise as the liquid temperature plateaus, giving a constant temperature difference between the heater surface and the bulk liquid.

Results of parametric variation of key experimental system parameters from select cases are shown in the following four figures: mass flux variation in Figure 13, heat flux variation at 70.0 bar in Figure 14, and at 150.0 bar in Figure 15 and Figure 16. Qualitatively, CTF void fraction predictions are better at higher mass fluxes and higher heat fluxes, and they are worse at lower mass fluxes. At both 70.0 bar and at 150.0 bar for varying heat fluxes and at moderate to high mass fluxes, the CTF predictions capture the void fraction development, with underpredictions at low void fractions and overpredictions at high void fractions. The effect of pressure shown in Figure 16 is more pronounced in CTF than in the experimental data in terms of the ONB location and void fraction development.

The overall void fraction comparison between the experimental data and CTF are shown in Figure 17. 


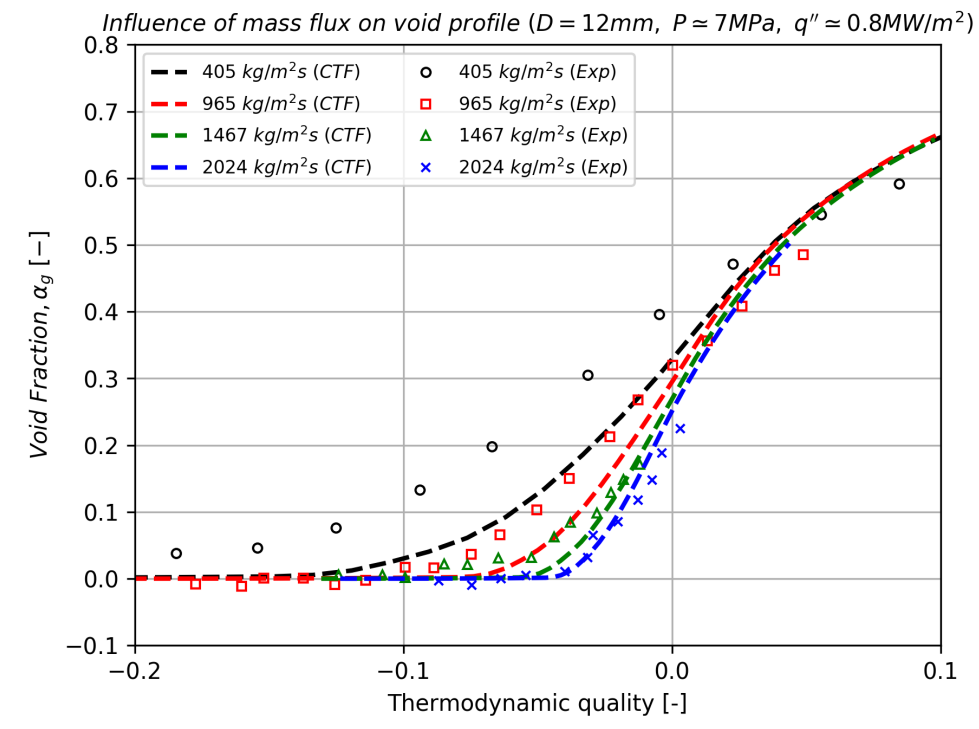

Figure 13. Comparison of CTF and experimental data for variation in mass flux at 70.0 bar and heat flux of $0.8 \mathrm{MW} / \mathrm{m}^{2}$.

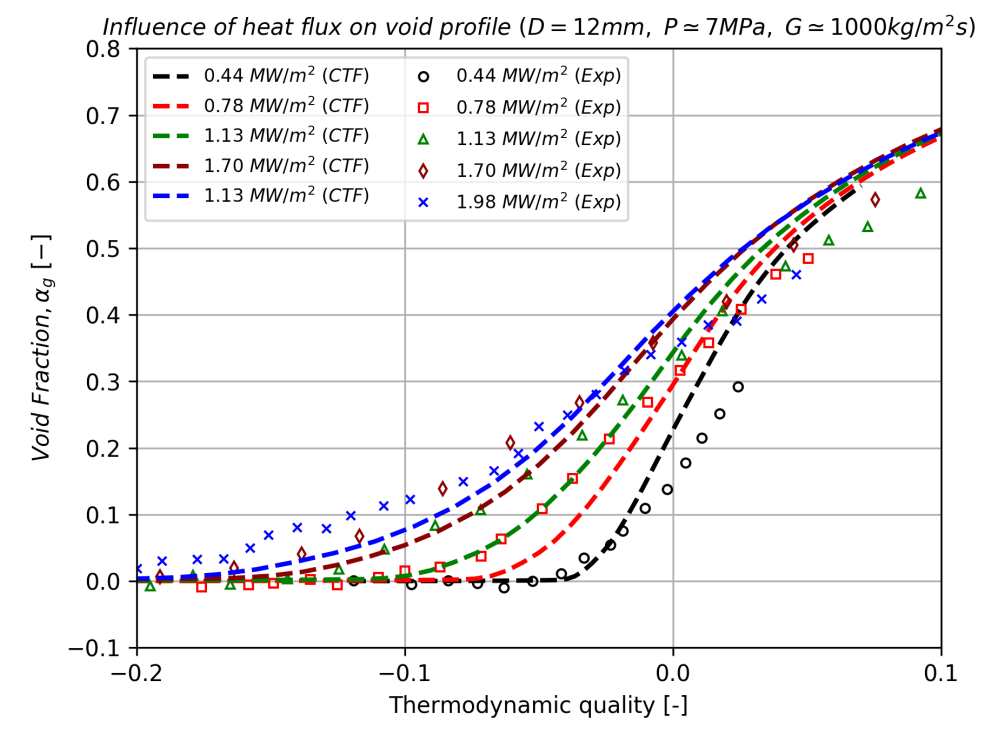

Figure 14. Comparison of CTF and experimental data for variation in mass flux at 70.0 bar and mass flux of $1,000.0 \mathrm{~kg} / \mathrm{m}^{2}$-s. 


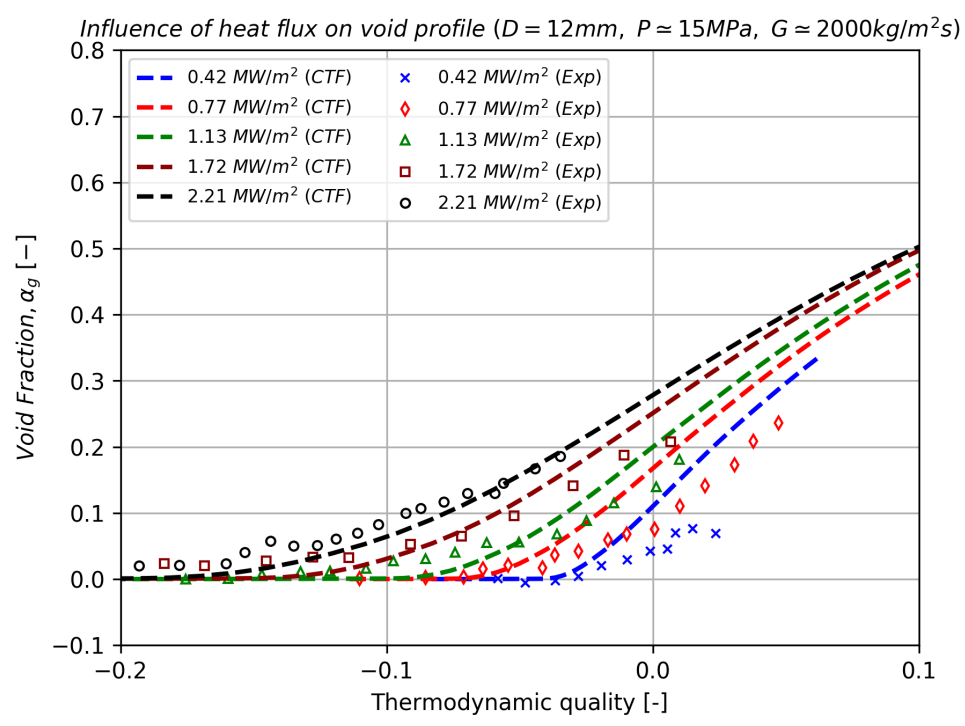

Figure 15. Comparison of CTF and experimental data for variation in mass flux at 150.0 bar and mass flux of $2000.0 \mathrm{~kg} / \mathrm{m}^{2}$-s.

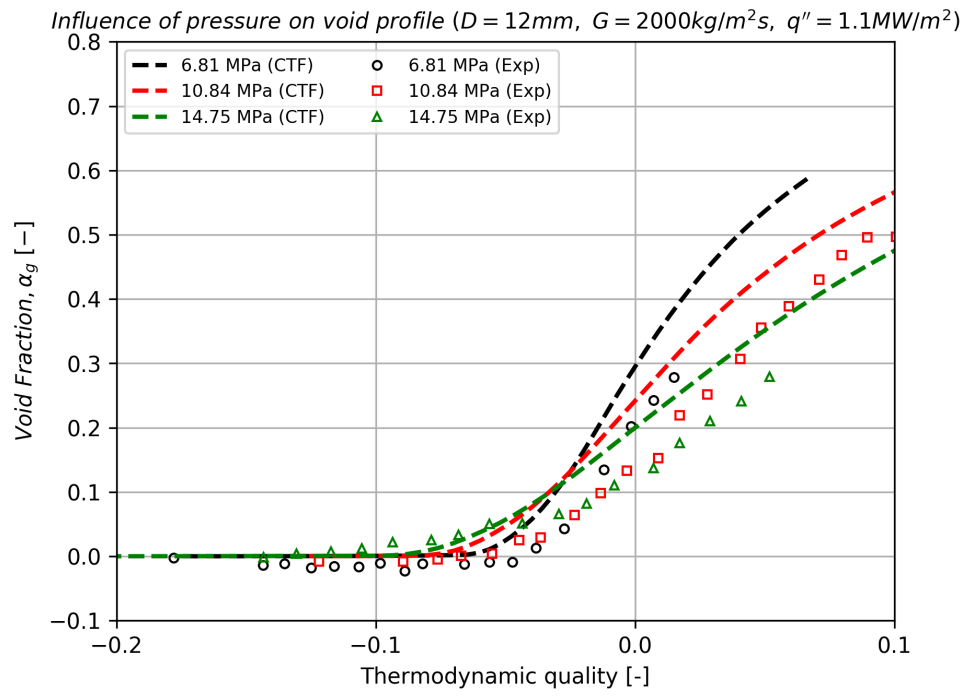

Figure 16. Comparison of CTF and experimental data for variation in system pressure at mass flux of $2000.0 \mathrm{~kg} / \mathrm{m}^{2}$-s and heat flux of $1.1 \mathrm{MW} / \mathrm{m}^{2}$. 


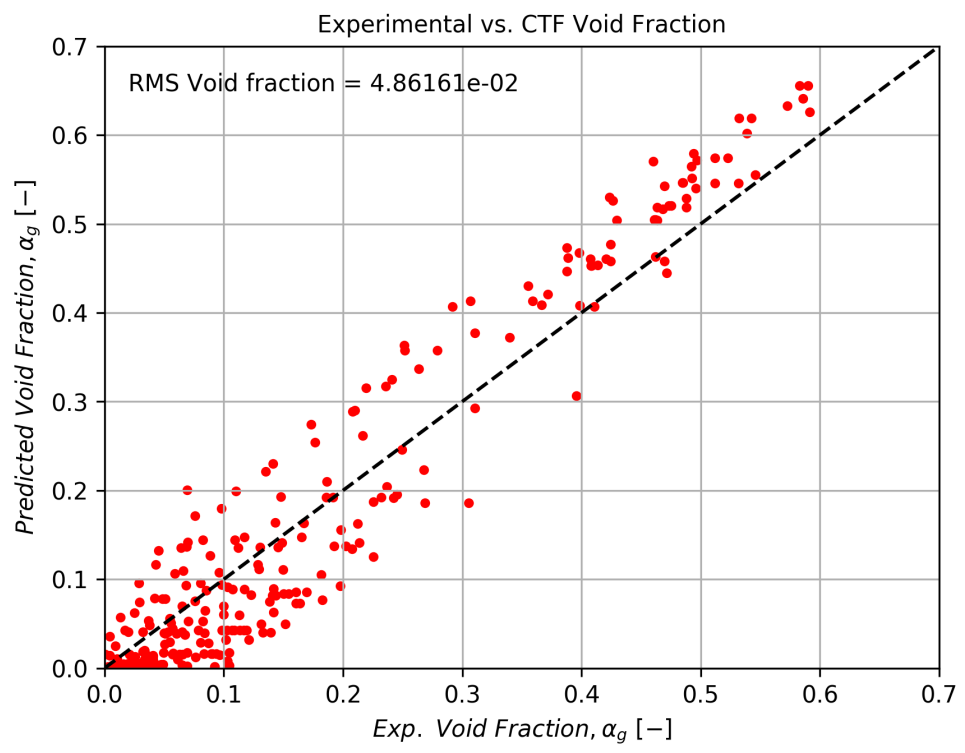

Figure 17. Overall comparison of CTF vs. experimental void fractions using the subcooled boiling model of Thom.

Since the void fraction data are available as a function of the equilibrium quality for Cases $13-38$, the corresponding CTF values were matched to within a relative tolerance of 10 percent. Similarly, for Case 1, the experimental and CTF flow enthalpies are matched to within a relative tolerance of 1 percent. It must be noted that all data points are used for Case 1 using the 1 percent criterion, while about 90 percent of the datapoints are matched for Cases 13-38 using the 10 percent criterion. These results use the default subcooled wall boiling model of Thom. The CTF comparison using the subcooled wall boiling of Chen is shown in Figure 18. For the other benchmarking studies in this chapter, the model of Chen overpredicts the wall temperature and subsequently the void fraction. For this dataset, the model of Chen does better with the wall temperature prediction for Case 1. Overall, the model of Chen predicts the void fraction more accurately at low voids, with a consistent overprediction at higher void fractions. The model of Thom has considerable scatter on either side of the 1:1 line at lower void fractions, with a consistent overprediction at higher void fractions, similar to the other benchmarking studies presented in this section.

The results of the Bartolomei validation seem to agree with existing CTF validation results when the mass flux is high. Void is overpredicted for all pressure levels in Figure 16, and Figure 17 indicates that more data points are overpredicted than underpredicted. However, the dataset reveals that at lower mass fluxes, void becomes underpredicted. The BFBT void distribution cases were all run at a similar mass flux, so this trend does not appear in that dataset. A similar comparison should be made on the PSBT Series 5, 6, and 7 datasets to determine if similar behavior exists. It was observed in PSBT Series 7 that void predictions near the unheated rod were greatly overpredicted, which may be related.

\subsubsection{Validation matrix driver}

While each category of validation tests includes a set of scripts to assist with model building and/or analyzing the test results and comparing them to experimental data, the automation for each test set was 


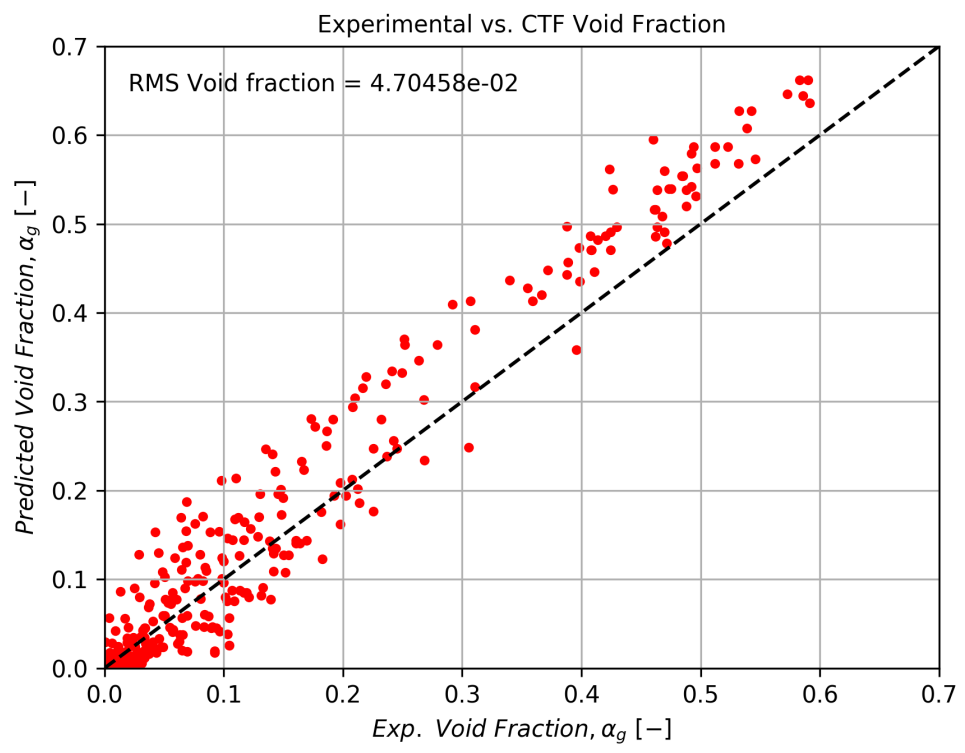

Figure 18. Overall comparison of CTF vs. experimental void fractions using the subcooled boiling model of Chen.

typically performed in a custom way. This proved to be problematic, as the test matrix continued to grow over time. For example, when a model is changed or a defect is encountered and fixed, it is necessary to re-run the validation matrix, update the results, and quantify the effect of the change. Having a different analysis approach for each set of tests is difficult, as each test must be run in a its own custom way each time, and each test set must be manually launched individually. As this project will involve modifying existing models or replacing them with new ones, it will be important to be able to quickly re-run the validation matrix and quantify the effect on comparison metrics.

To address this issue, a validation matrix driver utility was developed. This Python utility includes two core components:

1. ValidationTest: A base class that defines a set of tests. It is intended that the developer will extend this class for a test set that is added to the test matrix. This class includes methods that can be called for finding tests in the test set, processing test results, extracting summary statistics, and rebaselining gold results files for regression tests in the set.

2. runMatrix: The driver script that handles running all tests in the matrix. The utility will walk the test matrix directory structure in the CTF repository and will find all tests registered by the developer (class extensions of the ValidationTest abstract class). The driver will run tests in parallel on a personal computer or an high-performance computing (HPC) system using a job queuing system. The driver will finally generate summary statistics that give a high-level overview of how test results have changed since the last run in all tests, generate new figures for the CTF Validation Manual, and rebaseline results of regression tests while detailing the changes. This driver will also detect any cases that do not converge and will summarize any encountered errors during the process of running and analyzing tests.

So far, all of the major two-phase validation tests have been added to the testing matrix driver using this 
approach. The usage instructions from the driver utility summarize the options available to the script user.

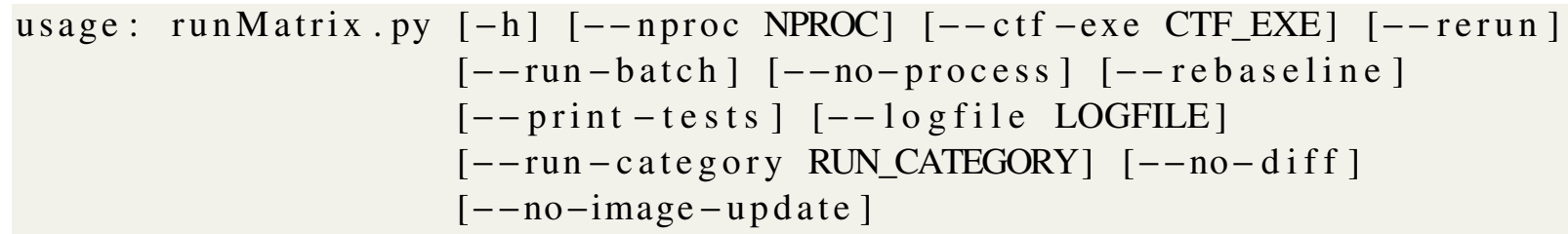

Runs the CTF validation matrix. It is assumed this script is run in the source directory. By default, this will run every validation test, perform all data processing steps that compare experimental and calculated results including generation of plots, diff all tests to gold files if that test is included as a regression test in the CTF CI, and make a printout summarizing which tests did not converge (if any) and what the differences were from gold files. All tests will be run in parallel according to user provided number of processors. Note that this driver script depends on other driver scripts defined by the developer for each test category. Adding new tests requires the developer to add new driver scripts that define the steps of running the tests, processing results, etc. The ValidationTest base class should be used to define the process of running a set of tests - See ValidationTest.py for more details.

optional arguments :

$-\mathrm{h},--$ help

-- nproc NPROC

$--\mathrm{ctf}$-exe CTF_EXE run the tests. If

-- rerun have a '.success', file which indicates the test was previously run successfully. Specify this flag to rerun all tests; even ones that were previously run successfully.

-- run-batch

Run all jobs using the PBS job scheduler (ross cluster only). Exits immediately after all jobs are submitted. User will need to run again to process results.

-- no-process

Disables processing of results.

-- rebaseline

If set, all gold files will be rebaselined with new test results.

- - print - tests

If set, script will only print the test categories found and do nothing else.

--logfile LOGFILE Name of the log file to write to

--run-category RUN_CATEGORY If specified, only run these test categories and not all in the matrix. The passed name should be the name of the module (use --print-tests to see names).

--no-diff If present, do not printout diff of test and gold files. show this help message and exit

Number of processors to use for the job.

will be used to 
--no-image-update If present, do not copy new images developed from post-processing current results to the validation document directory. 



\section{SUMMARY}

This report documents the immediate needs in CTF to make the code more applicable to BWR modeling and simulation. Needs are organized according to user-interface improvements and modeling improvements. User-interface improvements involve making improvements to the supported geometry features in CTF and the output of results to be consistent with the VERA approach for BWR-specific geometry. The most pressing issue in terms of geometry support is the addition of the capability to model part-length rods. While CTF is capable of modeling this geometry, the Xml2ctf preprocessor must be expanded to include support for this feature as defined in the VERAIn common input file. There are multiple options for modeling this geometry in CT, were investigated as described in this report. It is intended that the table-based approach will be used to capture the effect of the rod disappearing because it appears to be easier to implement into Xml2ctf and has little impact on the results compared to using a multi-section approach. Further testing will be performed by expanding on the current tests developed in this report so that they include two-phase flow. Other features that must be added to CTF include allowing the user to specify an inlet orifice map and modifying CTF to correctly print pin and channel location information to the VERA HDF5 file for visualization.

Preliminary testing conducted for CASL has revealed issues in overpredicting void and two-phase pressure drop. It is suspected that the CTF subcooled boiling model may be at least partially to blame for this overprediction. A review has been performed for the subcooled boiling modeling approaches used by three popular nuclear thermal-hydraulics analysis codes which casts some doubt on the approach used by CTF. In light of this review, suggestions for moving forward with modeling improvements are presented. This effort will mostly involve expanding on the two-phase validation matrix, including adding tests that measure void and rod surface temperature in tests modeling subcooled and saturated boiling. This will help to indicate areas where CTF can be further improved and will serve as a check on any improvements made. Furthermore, the data will be useful for any model recalibration that is performed. As part of this work, the two-phase validation tests have been expanded to include the Bartolemei dataset, which includes void measurements in tube geometry. A list of other potential tests to add has been prepared based on the results of a brief literary search.

Finally, a validation test driver utility was developed to facilitate an almost completely automated execution of the entire CTF validation matrix and processing of results to generate summary statistics and figures. This will streamline the process of evaluating new and improved models that are implemented into CTF. All new tests that are added to the matrix will be registered with this test driver. 



\section{REFERENCES}

\section{References}

[1] S. Bajorek et al. TRACE V5.1051 Theory Manual. US NRC, 2016.

[2] G.G. Bartolomei, V.G. Brantov, Y.S. Molochnikov, Y.V. Kharitonov, V.A. Solodkii, G.N. Batashova, and V.N. Mikhailov. An Experimental Investigation of True Volumetric Vapour Content with Subcooled Boiling in Tubes. Thermal Engineering, 29:20-22, 1982.

[3] A.W. Bennett, G.F. Hewlett, H.A. Kearsey, and R.K.F. Keeys. Heat Transfer to Steam-Water Mixtures Flowing in Uniformly Heated Tubes in which the Critical Hheat Flux Has Been Exceeded. Technical Report AERE-R 5373, U.K.A.E.A. Research Group, Atomic Energy Research Establishement, 1967.

[4] H. Christensen. Power-to-Void Transfer Functions. Technical Report ANL-6385, Argonne National Laboratory, 1961.

[5] J. Deshon. Simulated Fuel Crud Thermal Conductivity Measurements under Pressurized Water Reactor Conditions. Technical Report 1022896, Electric Power Research Institute, 2011.

[6] G.G.Bartolomei and V.M. Chanturiya. Experimental Study of True Void Fraction When Boiling Subcooled Water in Vertical Tubes. Thermal Engineering, 14:123-128, 1967.

[7] H. Herkenrath and W. Hufschmidt. Experimental Investigation of the Enthalpy and Mass Flow Distribution between Subchannels in a BWR Cluster Geometry (PELCO-S). Technical Report EUR-6585-EN, Commission of the European Communities, 1981.

[8] Z. Karoutas, Y. Sung, Y. Chang, G. Kogan, and P. Joffre. Subcooled boiling data from rod bundles. Technical Report 1003383, EPRI, 2002.

[9] J. E. Kelly, S. P. Kao, and M. S. Kazimi. THERMIT-2: A Two-Fluid Model for Light Water Reactor Subchannel Transient Analysis. Technical Report MIT-EL-81-014, MIT Energy Laboratory Electric Utility Program, 1981.

[10] B. Neykov, F. Aydogan, L. Hochreiter, K. Ivanov, H. Utsuno, and F. Kasahara. Nupec bwr full-size fine-mesh bundle test (bfbt) benchmark. Technical report, NUCLEAR ENERGY AGENCY, 2006.

[11] D. W. Radcliffe R. T. Lahey Jr., B. S. Shirlakar. Two-Phase Flow and Heat Transfer In Multirod Geometries: Subchannel and Pressure Drop Measurements in a Nine-Rod Bundle for Diabatic and Adiabatic Conditions. Technical report, General Electric, 1970.

[12] S. Rouhani. Void Measurements in the Regions of Sub-Cooled and Low-Quality Boiling. Part 1: Low Mass Velocities. Technical Report AE-238, Aktieboaget Atomenergi, Stokholm, Sweden, 1966.

[13] A. Rubin, A. Schoedel, M. Avramova, H. Utsuno, S. Bajorek, and A. Velazquez-Lozada. Oecd/nrc benchmark based on nupec pwr subchannel and bundle tests (psbt). Technical report, US NRC and OECD Nuclear Energy Agency, 2010.

[14] R. Salko, A. Wysocki, M. Avramova, A. Toptan, N. Porter, T. Blyth, C. Dances, A. Gomez, C. Jernigan, and J. Kelly. CTF Theory Manual. The North Carolina State University, 2017. 
[15] R. Salko, A. Wysocki, J. Gehin, M. Avramova, A. Toptan, N. Porter, T. Blyth, C. Dances, J. Magedanz, M. Gergar, C. Gosdin, C. Jernigan, J. Kelly, and S. Palmtag. CTF Validation and Verification. The North Carolina State University, 2017.

[16] C. Stewart, J. Cuta, S. Montgomery, J. Kelly, K. Basehore, T. George, and D. Rowe. VIPRE-01: A Thermal-Hydraulic Code for Reactor Cores. Battelle, Pacific Northwest Laboratories, 2007.

[17] Jorgen Wurtz. An experimental and theoretical investigation of annular steam-water flow in tubes and annuli at 30 to 90 bar. Technical Report Riso Report No. 372, Riso National Laboratory, Copenhagen, Denmark, 41978.

[18] S. Yagnik, P. Peturaud, and J. Garnier. New Experimental Studies of Thermal-Hydraulics of Rod Bundles (NESTOR). Part 2: Data Compilation of MANIVEL and OMEGA Test Results on $5 \times 5$ Bundle Equipped with Mixing Vane Grids. Technical Report 1019423, Electric Power Research Institute, 2009.

[19] W. Yao and C. Morel. Volumetric Interfacial Area Prediction in Upward Bubbly Two-Phase Flow. International Journal of Heat and Mass Transfer, 47:307-328, 2004.

[20] JunSoo Yoo. CFD Boiling Validation: Assessment and Discussion of the Present Baseline Boiling Model. Technical Report INL/EXT-18-51242, Idaho National Laboratory, 2018.

[21] X. Zhao and R. Salko. Validation and Benchmarking of CTF for Two-Phase Flow Using VIPRE-01. Technical Report CASL-U-2016-1184-000, Consortium for Advanced Simulation of Light Water Reactors, 2016. 